\title{
1 Small effect-size mutations cumulatively affect yeast quantitative traits
}

2 Bo Hua ${ }^{1,2}$ and Michael Springer ${ }^{1, *}$

$3{ }^{1}$ Department of Systems Biology, Harvard Medical School, Boston, Massachusetts 02115

$4 \quad{ }^{2}$ Systems Biology Graduate Program, Harvard University, Cambridge, Massachusetts, United

5 States of America

$6 *$ Corresponding author and Lead contact, Email: michael_springer@hms.harvard.edu

\section{Summary}

9 Quantitative traits are influenced by pathways that have traditionally been defined through genes that have a large loss- or gain-of-function effect. However, in theory, a large number of

11 small effect-size genes could cumulative play a substantial role in pathway function, potentially

12 by acting as "modifiers" that tune the levels of large effect size pathway components. To

13 understand the role of these small effect-size genes, we used a quantitative assay to determine

14 the number, strength, and identity of all non-essential genes that affect two galactose-

15 responsive (GAL) traits, in addition to re-analyzing two previously screened quantitative traits.

16 Over a quarter of assayed genes have a detectable effect; approximately two thirds of the

17 quantitative trait variation comes from small effect-size genes. The functions of small effect-size 18 genes are partially overlapping between traits and are enriched in core cellular processes. This 
19 implies that genetic variation in one process has the potential to influence behavior or disease

20 in seemingly unconnected processes.

21

\section{Highlights}

23 - Four yeast quantitative traits are affected by thousands of small effect-size genes.

24 - Small effect-size genes are enriched in core cellular processes

25 - The effects of these genes are quantitative trait-specific.

\section{Introduction}

28 What are all the genes that are involved in a trait? Classically, the pathways that contribute to a

29 trait, like those involved in signaling or development, were defined by genetic screens that

30 identified genes with loss- or gain-of-function phenotypes (Nüsslein-Volhard and Wieschaus,

31 1980). As screens became more quantitative, many alleles of both small and large effects size

32 where identified (Ehrenreich et al., 2010; Friedman and Perrimon, 2006).But, the methods to

33 validate and then determine the molecular function have remained laborious. Hence, research

34 has typically focused on genes on characterizing genes with large effect size. This has lead to a

35 potential bias that these large effect size genes dominate the behavior and variability in a

36 pathway. An alternative view is that cumulatively, the mainly overlooked small effect size genes 
37 significantly shape pathway function and population-level trait variation, and hence the genetic

38 architecture of a pathway is distributed not centralized (Figure 1). Until recently, it wasn't

39 possible to easily and comprehensively identify genes implicated in quantitative traits, making it

40 difficult to distinguish between these two hypotheses concerning the architecture of most

41 pathways.

42 The genetic architecture of quantitative traits has taken on increased importance as it has

43 become clear that many human traits, such as body mass index and traits that underlie

44 heritable human disease, are also quantitative. Numerous human traits and disease have been

45 studied using genome-wide association studies (GWAS) to uncover the loci containing causative

46 variants that are responsible for the genetic component of these traits (Hindorff et al., 2009). If

47 the genetic architecture of the underlying pathway were centralized, one would expect GWAS

48 would yield a small number of large effect-size genes typically of related function; if the genetic

49 architecture of a quantitative trait were distributed, one would expect GWAS would yield a

50 large number of small effect-size genes of often seemingly unrelated function. In some diseases,

51 e.g. age-related macular degeneration (AMD), GWAS indeed identified several common alleles

52 of large effect size that explain about half of the disease risk to siblings of affected individuals

53 (Maller et al., 2006). This would support the view of centralized signaling pathways. But, in

54 many cases, GWAS has yielded many small effect-size variants with low odd ratios (Hindorff et

55 al., 2009), and additionally many identified loci have not included genes with an obvious

56 connection to disease (Cooper and Shendure, 2011; Edwards et al., 2013). These results are

57 consistent with the hypothesis that the gene architecture of some pathways underlying human 
58 traits is distributed. Direct experiments to separate between these two hypotheses can help

59 frame our expectation for the results from these association studies.

60 Model organisms should be a powerful set of tools for defining the architecture of quantitative

61 traits. Several studies in yeast (Bloom et al., 2013; Ehrenreich et al., 2010) show that linkage

62 analysis has the potential to identify most of the causative loci needed to explain trait variation

63 between two natural yeast isolates. But these studies, like human GWAS, are limited by

64 recombination block size and sample size, and hence are not ideal for identifying causative

65 genes or the exact number and identity of small effect-size loci. As an alternative approach,

66 deletion libraries have been used to assess the role of every yeast gene. These studies have

67 been transformative for defining the function of unknown genes (Botstein and Fink, 2011) and

68 for showing that many processes in yeast are genetically interconnected (Costanzo et al., 2010;

69 2016). While informative, the assays that are typically performed, e.g. colony size assay, are not

70 quantitative enough to accurately determine the effect size of every mutant. Hence whether

71 this interconnectedness has a significant role in pathway function is still unclear.

72 In this work, we quantified the effect sizes of all non-essential yeast genes on several traits.

73 Instead of identifying existing genetic variation in natural populations, we used a yeast deletion

74 library to measure with high precision the magnitude of effect of all non-essential genes on a

75 quantitative trait, which we refer to as gene effect size. By its design, this approach identifies all

76 the genes whose loss-of-function has the potential to influence a trait, and the effect size

77 distribution of these genes. We found that all four traits we analyzed have an exponential

78 distribution of effect sizes. The consequence of these results is that cumulatively, small effect- 
79 size can significantly contribute to pathway function. Gene Ontology(GO) analysis and

80 additional experiments showed that many of these small effect-size mutations are involved in

81 core cellular processes and affect quantitative traits in a trait-specific, not generic, manner. In

82 natural populations, phenotypic variation is influenced by the actual existing variants; this

83 natural variation is more complex than our deletion library. We showed through simulation that

84 our analysis based on deletion mutants, given modest assumptions, yields an effect size

85 distribution that is close to the distribution that would be observed for other sources of genetic

86 variation.

\section{Results}

\section{A large fraction of genes can influence multiple biological processes}

89 A large number of screens have been performed with the yeast deletion library (Giaever and

90 Nislow, 2014). These screens could potentially serve as a rich source of data for determining the

91 effect size of each gene on many traits. Reanalyzing this data, we found that, due to

92 measurement noise, most of these studies do not have the power to determine the full gene-

93 level effect size distribution (Supplemental Information). This is not surprising as the goal of

94 most studies was to identify genes of large effect size rather than attempting to identify all

95 genes of any effect size. Therefore, to determine the number of genes that can affect a

96 pathway, we created a reporter library with which we could quantitatively measure the

97 response of cells to galactose (GAL). We systematically constructed a library of strains deleted

98 for all non-essential yeast genes each containing a YFP reporter driven by the GAL1 promoter

99 (GAL1pr-YFP). We then assayed the bimodal YFP response (Acar et al., 2005; Escalante-Chong et 
al., 2015) in single cells growing in mixtures of glucose and galactose by flow cytometry (Figure studies (Breslow et al., 2008; Jonikas et al., 2009), one on growth rate in rich medium and one on the unfolded protein response (UPR), that had a signal-to-noise ratio that was sufficiently

104 large to determine the effect size distribution.

Principal component analysis of the results from our GAL response screen highlighted three

106 distinct traits (Figure S1). These traits, corresponding to: 1) the fraction of cells that are induced

107 above background; 2) the induction level of the induced ('on') peak; and 3) the background

108 level of the uninduced ('off') peak (Figure 2C, Supplemental Information). The signal-to-noise

109 ratio of the first two metrics was sufficient to calculate an effect size distribution for a large

110 number of genes. We will refer to these two separable GAL traits as the "induced fraction" and

111 the "induction level" (Figure 2D).

112 Each of the four traits - the induced fraction, induction level, growth rate, and UPR - considered

113 in isolation, was influenced by a large number of deletion strains (Figure 2E and F); the

114 distribution of mutant effects was continuous. Based on a comparison of the measured effect

115 sizes and the measurement noise estimated from biological replicates, 19\% (796 of 4201), 16\%

116 (735 of 4562), 16\% (689 of 4162), and 20\% (849 of 4162) of non-essential genes screened, at a

$1170.5 \%$ false discovery rate, affect the growth rate in rich media, unfolded protein response,

118 induced fraction in GAL, and induction level in GAL respectively. Together the two GAL traits are

119 composed of 1104 unique genes. Interestingly, if we used a single composite trait, i.e. mean

120 expression, to quantify the GAL response, fewer genes (593 of 4162) were identified, 
121 highlighting the utility of sub-classifying higher-level phenotypes that might be composed of

122 separable traits each controlled by distinct genetic factors (Supplemental Information). To

123 obtain a more accurate estimate of how many genes can quantitatively affect each of the traits,

124 at the sacrifice of knowing the identity of the genes, we determined the area of the normalized

125 effect size distribution that is outside the normalized measurement noise distribution (Figure

126 S2). From this, we estimate that the fraction of genes affecting the growth rate in rich media is

$12762 \%$, unfolded protein response is $23 \%$, induced fraction in GAL is $28 \%$, and induction level in

128 GAL is 34\% (Supplemental Information). Together these results highlight that a large fraction of

129 the protein-coding genes has the potential to quantitatively affect a trait.

130 As a final method to determine the number of genes that influence our four traits we

131 determined whether the effect size distributions could be explained by a simply analytical

132 function. To minimize the effect of measurement noise on measured effect sizes, we first

133 focused our analysis on the genes whose effect size was significantly different from

134 measurement noise. Interestingly, we found that the effect size distribution for all four traits

135 was well fit by an exponential distribution $\left(R^{2}=0.91-0.96\right.$, Figure $2 E$ an $F$, dotted line). When

136 extrapolating the exponential fit into the measurement noise, it predicts that $27-33 \%$ of genes

137 affect each of our four traits, similar to the orthogonal estimates above. Adding measurement

138 noise to the exponential distribution (Figure $2 \mathrm{E}$ and $\mathrm{F}$, blue line) well fit the full measurement

139 distribution $\left(R^{2}=0.92-0.98\right)$. Therefore, a parsimonious explanation of our data is that the effect

140 size distribution of a quarter to half of genes is exponential. Half to three quarters of all genes

141 have little to no effect. 


\section{Small effect-size genes can influence pathway function}

143 The shape of the determined effect size distributions implies that each of the four traits is

144 affected by genes with a continuous distribution of effect sizes ranging from a small number of

145 large effect-size genes to a large number of small effect-size genes. It has been questioned

146 whether even such a large number of small effect-size mutants could substantially contribute to

147 the functionality of a pathway (Crow, 2011). The answer to this question depends on the exact

148 shape of the measured effect size distribution (e.g. Figure 1C II versus III). We therefore

149 determined the number of genes that are cumulatively important for pathway function. To do

150 so, we devised a method to quantify the impact of each gene, which is similar to the one used

151 to quantify allelic contribution to narrow-sense heritability in a GWAS (Lynch and Walsh, 1998).

152 In the calculation, we first assumed a population of cells with independent and randomly

153 assorting alleles. We assumed only two possible alleles for each gene, i.e. deletion or wild-type

154 (a more complex model will be considered below). We then calculated each gene's contribution

155 to the trait variation in the population as $2 \beta^{2} f(1-f)$ (Lynch and Walsh, 1998), where $\beta$ is the

156 effect size and $f$ is the allele frequency, assuming that each allele has a frequency of $50 \%$ and no

157 epistasis (Figure 3A). For our four traits, using the measured effect size for each gene, we find

158 that 257-352 genes with the largest effect sizes, representing 5.6-8.5\% of screened genes, are

159 needed to explain $80 \%$ of total computed variation (Figure 3B and C, and Figure S4). If human

160 traits behave similarly to our yeast deletions, we would estimate that the number of genes

161 required to explain most of the heritability of a quantitative trait is in the range of 1200-1900

162 genes. Interestingly, our estimate is concordant with estimations from GWAS. For example, the 
163 current estimate for human height, the best characterized human trait, is that $4231 \mathrm{Mb}$ loci are

164 involved. Yet this explains only $20 \%$ of the heritability. This result suggests that both in yeast

165 and humans, some pathways and traits resemble the distributed architecture from Figure 1C III;

166 i.e. a large number of genes of slowly diminishing effect size contribute to pathway function

167 and trait variation.

168 Given their individual small effect size, our analysis also suggests that a significant portion of

169 the genes that account for pathway function would not typically be considered to be

170 contributing to each trait. Classical genetic screens identified only a fraction of the genes that

171 have the potential to significantly affect each of the two GAL traits. A compiled list of the 50

172 genes previously identified as affecting the GAL pathway (Supplemental Information) explained

173 only $32.0 \%$ and $11.7 \%$ of variation in the induction level and induced fraction traits respectively.

174 Similarly, in the unfolded protein response, genes whose products localize throughout the

175 secretory pathway (ER and Golgi) explain only $27.1 \%$ of variation, further suggesting substantial

176 roles of additional genes/processes. Hence, much of the variance occurs in genes we term non-

177 trait-specific, i.e. genes that are not typically considered to be physiologically related to the trait.

178 This is consistent with previous GWAS that identified putative causative loci that in some cases

179 contained genes that were obviously trait-specific but in other cases were involved in general

180 cellular processes. For example, human height is affected by variants in genes that underlie

181 skeletal growth defects (trait-specific), as well as general pathways such as the Hedgehog

182 pathway (non-trait-specific) (Lango Allen et al., 2010). Surprisingly, our analysis suggests that

183 the non-trait-specific processes can have a larger aggregate effect than trait-specific pathways. 
184 A potential caveat to these estimates is that the GAL phenotypes of ten mutants are either fully

185 induced or uninduced, causing the effects of these genes to be underestimated. These ten

186 genes have previously described influences on the GAL pathway. GAL1, GAL3, GAL4, GAL80,

187 REG1, and SNF3 are involved in either glucose or galactose signaling. HSC82 and STI1 interact

188 with the HSP9O co-chaperone that has been shown to influence the GAL pathway (Gopinath

189 2016). SNF2 is a SWI/SNF chromatin remodeling complex that was previously suggested to be

190 involved in nucleosome occupancy on GAL promoter (Bryant et al., 2008). GCN4, is a general

191 transcription factor that responds to amino acid starvation. We believe in most cases this

192 caveat does not affect our results. Because, the loss-of-function effect size of these alleles is

193 effectively infinite, they will behave as Mendelian not quantitative alleles. Instead, for any

194 quantitative traits, the predominant alleles of these Mendelian loss-of-function genes must be

195 hypomorphic alleles. Indeed, when we assume hypomorphic allele effect sizes for these genes

196 by randomly sampling from the tail of the fitted exponential distribution, we only observed a

197 modest increase in total trait variation $(<3 \%)$.

198 Gene deletions in core cellular processes affect quantitative traits

199 What are the functions of these 'pathway modifiers' we identified? Are they genes that have

200 general effects on all traits or are they specific to one or a subset of traits? We found that non-

201 trait-specific processes often affect more than one trait. All pairs of traits share significantly

202 more genes that affect their behaviors than expected $\left(p<10^{-65}\right.$, one-tailed hypergeometric test).

203 While only 2 genes would be expected by chance, 113 genes were shared by all traits (Figure

204 4A). These genes also overlap significantly with "hub" genes identified from genetic interaction 
205

206

207

208

209

210

211

212

213

214

215

216

217

218

219

220

221

222

223

224

225

network (between 140 and 257 out of 380 hubs genes are significant for each of the four traits, $\mathrm{p}<10^{-47}$, hypergeometric test) (Costanzo et al., 2010). We used Gene Ontology to ask if shared non-trait-specific genes were enriched for specific biological processes. Indeed, many processes were enriched (Table S1), including translation (GO:0006412), regulation of metabolism (GO:0031323), and transcription (GO:0006351). Although this has not previously been extensively characterized, it is not surprising that these traits might be altered by perturbations in some core cellular processes.

The identification of these core cellular processes as having potential to explain a significant amount of trait variation could be fundamental or trivial. It could reflect an architecture where many biological traits integrate many external and internal factors as inputs (e.g. the GAL pathway responding not just to galactose but glucose, redox status, ribosome capacity, ER capacity, etc.). Alternatively, as the expression of a large fraction of yeast genes is affected by growth rate control (Keren et al., 2013; Regenberg et al., 2006; Slavov and Botstein, 2011), a trivial explanation could be that the effect on the UPR and GAL traits is solely an indirect effect of a growth rate defect (Figure S4). Our data do not support growth rate as the sole factor explaining our results. Between $40 \%$ and $60 \%$ of gene deletions affect our GAL and UPR traits without affecting growth and vice versa (Table S2). Furthermore, for genes that affect both growth rate and any of the other traits, there is no correlation in effect size between the two effects $\left(R^{2}<0.02\right.$, S Figure 7B-D). These observations argue against the idea that defects in growth are the main reason that non-trait-specific genes affect the behavior of traits. The involvement of many non-trait-specific genes instead suggests that many signaling pathways 
226 integrate a much larger set of cellular inputs than the single input for which the pathways are

227 named.

228 Perturbation of core cellular processes can have trait-specific effects

229 Consistent with the idea that traits integrate a number of inputs in a trait-specific manner, we

230 find that biological processes often affect more than one trait, but importantly not all traits.

231 Using a spatial clustering algorithm in the four-trait space (Figure 4B-C), we found an

232 enrichment in core cellular components (Table S3), such as ribosomal genes (GO:0002181),

233 mitochondrial genes (GO:0005743), mannosyltransferases (GO:0000030), genes that affect

234 histone exchange (GO:0000812) or proteasome assembly (GO:0043248), and genes involved in

235 peptidyl-diphthamide synthesis (GO:0017183). Each of these sets of genes had a separable

236 direction in this 4-dimensional space suggesting each process is responding distinctly to the

237 mutations (Figure 4D). For example, the 89 genes involved in cytoplasmic translation

238 (GO:0002181) were enriched in 3 out of 4 quantitative traits, namely the unfolded protein

239 response, growth rate in rich media, and GAL induction level, but not GAL induced fraction (40,

24021,37 and 3 genes respectively out of the top 300 genes). Conversely, mitochondrial inner

241 membrane genes (GO:0005743) are enriched in the GAL induced fraction but not growth rate,

242 unfolded protein response, nor GAL induction level (21 versus 3, 1, and 4 respectively out of the

243 top 300 genes).

244 Furthermore, the same core processes can have distinct effects on different traits. For example,

245 at first glance, one might expect mutations in ribosomal genes to affect the level of induction of

246 a pathway (e.g., by altering the expression level of all genes) but not the fraction of cells 
247 induced. Indeed, this is the case for the GAL response. But, when we examined the effect of the

248 same mutants on a phosphate responsive (PHO) promoter, PHO84pr, we obtained a different

249 result (Figure 5). The PHO84 promoter responds to phosphate limitation in a bimodal manner

250 and can therefore be characterized in the same way as we characterize the GAL response. The

251 effects of ribosomal mutants on the induction level of PHO84pr-YFP are significantly less than

252 for GAL1pr-YFP (Figure 5B versus C; Figure 5E and Figure S5, $\mathrm{p}=3 \times 10^{-10}$, two-tailed t-test).

253 Instead, ribosomal mutants affect the PHO induced fraction and the level of expression of the

254 uninduced cells (Figure 5C and examples in Figure 5D). In support that these results are a direct

255 consequence of perturbation of ribosomal function, cycloheximide, a small molecule inhibitor

256 of the ribosome, phenocopies the results of ribosomal gene deletions on both the GAL and PHO

257 pathways (Figure 5B-D). While this result at first may seem counter-intuitive, these results

258 could be explained if ribosomal proteins differentially impacted the expression level of positive

259 versus negative regulators of a trait. In total, this suggests that variation in genes involved in

260 core cellular processes could have both generic and pathway specific effects.

\section{Extension to other sources of genetic variation through simulation}

262 We next wished to determine to what extent our results generalize to genetic variation beyond

263 the complete loss-of-function variants we experimentally measured. Genetic variation in

264 natural population is more complex genetically than the deletion library we analyzed. To

265 generalize our results to account for a broader range of genetic variation, we developed a

266 model where we accounted for 1) other types of alleles, i.e. hypermorphs and neomorphs as

267 originally proposed by Muller (Muller, 1932), 2) variable number of alleles per gene, and 3) 
268 variable allele frequencies in the population (Figure 6). While the actual molecular cause of the

269 variation can come from many sources, e.g. single nucleotide polymorphisms (SNPs), copy

270 number variation, and indels, for the purpose of understanding the genetic architecture, it is

271 only important to understand the effect of the genetic change on the trait, and hence for

272 simplicity we will refer to all genetic variants as SNPs. Additionally, we assumed all SNPs

273 contribute linearly to the trait with no epistasis. This assumption is based on the fact that a

274 linear model using all SNPs genotyped in human height GWAS can explain a large fraction of

275 height heritability (Yang et al., 2015; 2010).

276 To instantiate the model (Figure 6) a series of functional forms and constants were assumed for

277 each of the potential variables. The number of SNPs that affect a given gene was chosen from a

278 Poisson distribution to reflect variable number of alleles observed in human genome

279 (Sachidanandam et al., 2001). The effect size of hypomorphic SNP was modeled by multiplying a

280 beta distributed random variable by the actual measured effect size of each affected gene. In

281 this way, the maximum effect size was the complete loss-of-function and the minimum effect

282 size was zero. A beta distribution was chosen to allow modeling of a wide range of different

283 shaped distributions (Figure 6). To simulate neomorphic (gain-of-function) SNPs, we randomly

284 selected a fraction SNPs, and reassigned their effect sizes with the effect size of randomly

285 chosen SNPs. Lastly, the allele frequency for each SNP was chosen from a beta distribution.

286 In each simulation, we calculated the explained trait variation for each SNP, and then summed

287 up all the SNPs for a single gene to obtain the explained variation for each gene. We then varied

288 the parameters in each of the distributions of the variables introduced above. Specifically, we 
289 used Latin hypercube sampling to scan the parameter space of the distributions (blue dots,

290 Figure 6), and then compared the number of genes that explain $80 \%$ of trait variation obtained

291 from this model and our experimental results (Figure 3). The results from our simulation show

292 variation in the fraction of neomorphs dominates variation in the model. However, as long as

293 this fraction is below 5\%, the results of the simulation do not vary from the experimental

294 results by more than $17 \%$. Neomorphic alleles are typically assumed to be rare. In order to

295 determine the potential impact of the other parameters in our model, we fixed gain-of-function

296 rate to be 5\%. Resampling the other five parameters, we found that the average number of

297 SNPs per gene is the second largest source of variation in our model. However, as long as on

298 average 5 SNPs exist per gene in the population, the effect is negligible (orange samples in

299 Figure 6B). Large-scale sequencing efforts have now identified $\sim 20$ million genetic variants in

300 humans (Sherry et al., 2001). Even if 99\% of these variants were neutral, there would still be

301 enough SNPs per gene on average to support our conclusions. From this, we determined that

302 our estimate of number of genes that influence a trait from our knockout data is largely

303 insensitive to the parameters of our model, and quantitative analysis of complete loss-of-

304 function alleles should be informative even for the analysis of less severe and of rare alleles.

305 Discussion

306 In this work we sought to determine all the genes that can influence a pathway underlying a

307 quantitative trait. Depending on the number of genes and the magnitude of the effect,

308 pathways could in principle have a centralized or distributed architecture (Figure 1). To address

309 this question we determined the effect size distribution of deletion mutants for four 
quantitative traits in yeast. We did this by measuring the response to galactose at the single-cell

311 level for each deletion strain from the yeast library and by reanalyzing two additional

312 quantitative screens that measure competitive growth rates (Breslow et al., 2008) and the

313 unfolded protein response (UPR) (Jonikas et al., 2009) in the deletion library. We found that in

314 all four cases, the distribution of effect sizes is such where a quarter to half of the genes follow

315 an exponential distribution, with the rest of the genes having a negligible effect size (Figure 2).

316 Based on a simple model to calculate heritability, we found this result implies that a large

317 number of genes (5-9\% of all genes) would be needed to cumulatively explain at least $80 \%$ of

318 trait variation (Figure 3). Our results imply that there is a significantly larger subset of genes

319 that affect each trait than previously appreciated, but that individually their effect is difficult to

320 detect by less quantitative experimental methods. The results provide evidence for pathways

321 having a distributed, rather than centralized, genetic architecture.

322 A distributed pathway architecture suggests that many genes that are not typically considered

323 part of a pathway, such as the GAL pathway, could still play an important role in pathway

324 function. We found that these "pathway modifiers" were enriched in several core cellular

325 processes (Figure 4). Given the pleiotropic nature of these processes, it is not surprising that

326 these genes can influence multiple traits. Unexpectedly, however, we found that a mutant in a

327 core cellular process can have trait-specific consequences; e.g. a ribosomal mutant affects the

328 induction level in the GAL response, but the induced fraction in the PHO response (Figure 5).

329 This implies that, instead of making cells 'sick', biological processes underlying quantitative

330 traits are likely affected by a large number of inputs that have the potential to act in a trait-

331 specific manner. 
332 Previous work had found that yeast traits were affected by fewer genes than we report here.

333 Work by Bloom et al. used linkage analysis to identify quantitative loci underlying 46 yeast traits,

334 and found a median of 12 loci affected each trait (Bloom et al., 2013). While it is possible that

335 our four traits happen to be more complex than the traits that were analyzed by Bloom et al.,

336 we believe the differences result from the applied methods. If either the two yeast strains used

337 in the linkage analysis of Bloom et al. are more related than two random isolates in a natural

338 population or if the traits analyzed were under strong selection, this would lead to an

339 underestimation of the number of genes. Because we are using a deletion library, we avoid the

340 confounding effect of selection and the biases due to the limited number of alleles between

341 two natural isolates. We therefore believe that the discrepancy between the results of these

342 two works is at least in part due to the applied methods, in particular selection on growth rates.

\section{Mendelian vs. quantitative trait}

344 A distributed genetic architecture, as observed in this study, has implication for patterns of

345 genetic inheritance. Different individuals can have different numbers of alleles and the effect

346 size of the strongest alleles can be different. Therefore, the expectation should be that the

347 same trait, when examined in a pairwise manner between many individuals, should exhibit a

348 range of segregation patterns from Mendelian to quantitative depending on the number and

349 strength of the alleles. Indeed, this exactly what was recently observed for multiple traits in

350 crosses between yeast strains (Hou et al., 2016). Furthermore, one should expect a smaller

351 number of genes that contribute to a quantitative trait will have rare alleles that make the trait

352 behave as a Mendelian trait. Indeed, this has also been found that many quantitative loci 
353 associated with normal human height variation contain genes underlying syndromes

354 characterized by abnormal skeletal growth (Lango Allen et al., 2010).

\section{Application to human genetics}

356 Our results suggest that the number of genes that can influence a trait, when extrapolated to

357 humans, is 1500. However, our results were focused on a single-celled microbe that has a

358 more compact genome with a smaller number of protein-coding genes than metazoan

359 genomes. To what extent might our observations generalize to human genetic variation, given

360 the differences in genome architecture and complexity? Do human traits, especially ones

361 involved in important human disease, also have such a distributed underlying genetic

362 architecture? One way to assess whether the genetic architecture of yeast and human traits is

363 different is to compare the number of genes and their corresponding effect size distribution.

364 While a small number of human diseases or traits can be explained by a small number of

365 causative genes, e.g. three genes explain $50 \%$ of the genetic risk in macular degeneration

366 (Maller et al., 2006), many traits are poorly explained by a small number of genes. For example,

367 a GWAS on human height found that 423 loci explained less than $20 \%$ of total heritability

368 (Wood et al., 2014). Similarly, 163 loci only explain 14\% of heritability in Crohn's disease (Jostins

369 et al., 2012), and 100 loci, excluding major histocompatibility complex, explain less than 6\% of

370 heritability in rheumatoid arthritis (Okada et al., 2014). Since the explained fraction of

371 heritability is far less than $100 \%$ in all these studies, it is difficult to accurately estimate the

372 number of loci required to explain a majority of heritability in a human trait, but a reasonable 
373 estimate would be in the thousands. This suggests that the fraction of genes involved in a

374 quantitative trait is similar in yeast and humans.

375 While the effect size distribution of human traits is poorly defined it is consistent with our

376 results. Park et al. devised a method to determine the effect size distribution by taking into

377 account all identified alleles and the power to have detected these alleles. From this they

378 concluded that the effect size distribution alleles affecting human traits are monotonically

379 increasing (Park et al., 2010). The range of possible distribution discussed in that work is

380 consistent with an exponential distribution. While there is no good human data exists on the

381 distribution of small effect size alleles, gene essentiality can be used as a rough comparison of

382 the relative distribution of strong effect size allele between yeast and humans. Further

383 supporting the similarity in effect size distributions, the number of essential genes in yeast and

384 humans is similar. In total we believe this supports the idea that while the human genome is

385 more complex than yeast, differences in genetic architecture are likely subtle and quantitative

386 not large and qualitative.

387 Implication of a distributed genetic architecture on human disease

388 High-throughput genetic interaction maps have suggested that cellular processes are deeply

389 interconnected (Costanzo et al., 2016; 2010). But, it was not determined whether these

390 connections were strong enough to be physiologically relevant. Our results demonstrate that

391 cumulatively many genes of small effect size can make significant contributions to quantitative

392 traits. Importantly, the effect sizes of these variants are not infinitesimal, and therefore we

393 believe that increased power in GWAS would likely capture a significant portion of the missing 
394 heritability. This conclusion is consistent with work from Yang et al., which has shown that

395 human genetic variants tagged in GWAS on body mass index is capturing the vast majority of

396 heritability even if it is underpowered to identify the causative loci (Yang et al., 2015). Of course,

397 increased power alone will not help identify which SNPs within a locus is causative.

398 Given that so many genes can affect a trait, a second expectation is that causative small effect

399 size loci should be shared between many but not all traits. Indeed, correlation among genetic

400 variants has been observed in a recent study using 24 human traits (Bulik-Sullivan et al., 2015).

401 Interpreting these results has been challenging as these genetic correlations could arise from

402 either a direct causative link between the two diseases or shared genetic factors. Our results

403 suggest that these correlations can result from shared genetic factors that are enriched in core

404 cellular processes. This means that there could be power in searching for processes that are

405 significantly enriched between diseases that wouldn't typically be thought of as related. Finally,

406 the spectrum of defects seen in some complex diseases could arise from the specific

407 combination of small effect alleles in each individual.

408 In summary, our work provides a system-level perspective into the architecture of a

409 quantitative trait. In contrast to most other works that focused on existing genetic variants, our

410 work quantitatively determined the contribution of loss-of-function alleles. With further

411 development of gene editing technologies and disease models, it will be interesting to test

412 these conclusions in more complex systems. 
414 Author contribution. B.H. and M.S. designed the experiments. B.H. performed the experiments.

415 B.H. and M.S. analyzed results and wrote the manuscript.

416 Acknowledgments. The authors thank Rebecca Ward, Yarden Katz for critically reading the

417 manuscript; the Springer lab for helpful discussions; and Shervin Javadi and Stratedigm for flow

418 cytometry assistance. B.H. and M.S. are funded by National Science Foundation Grant 1349248;

419 and by National Institutes of Health Grant RO1 GM120122-01. The authors have declared that

420 no competing interests exist.

Acar, M., Becskei, A., van Oudenaarden, A., 2005. Enhancement of cellular memory by reducing stochastic transitions. Nature 435, 228-232. doi:10.1038/nature03524

Bloom, J.S., Ehrenreich, I.M., Loo, W.T., Lite, T.-L.V., Kruglyak, L., 2013. Finding the sources of missing heritability in a yeast cross. Nature 494, 234-237. doi:10.1038/nature11867 Genetics 189, 695-704. doi:10.1534/genetics.111.130765

Boyle, E.I., Weng, S., Gollub, J., Jin, H., Botstein, D., Cherry, J.M., Sherlock, G., 2004. GO::TermFinder--open source software for accessing Gene Ontology information and finding significantly enriched Gene Ontology terms associated with a list of genes. Bioinformatics 20, 3710-3715. doi:10.1093/bioinformatics/bth456

Breslow, D.K., Cameron, D.M., Collins, S.R., Schuldiner, M., Stewart-Ornstein, J., Newman, H.W., Braun, S., Madhani, H.D., Krogan, N.J., Weissman, J.S., 2008. A comprehensive strategy enabling high-resolution functional analysis of the yeast genome. Nature Methods 5, 711718. doi:10.1038/nmeth.1234

Bryant, G.O., Prabhu, V., Floer, M., Wang, X., Spagna, D., Schreiber, D., Ptashne, M., 2008. Activator control of nucleosome occupancy in activation and repression of transcription. PLoS Biol 6, 2928-2939. doi:10.1371/journal.pbio.0060317

Bulik-Sullivan, B., Finucane, H.K., Anttila, V., Gusev, A., Day, F.R., Loh, P.-R., ReproGen Consortium, Psychiatric Genomics Consortium, Genetic Consortium for Anorexia Nervosa of the Wellcome Trust Case Control Consortium 3, Duncan, L., Perry, J.R.B., Patterson, N., Robinson, E.B., Daly, M.J., Price, A.L., Neale, B.M., 2015. An atlas of genetic correlations across human diseases and traits. Nature Genetics 47, 1236-1241. doi:10.1038/ng.3406 
Cooper, G.M., Shendure, J., 2011. Needles in stacks of needles: finding disease-causal variants in a wealth of genomic data. Nat Rev Genet 12, 628-640. doi:doi:10.1038/nrg3046 Costanzo, M., Baryshnikova, A., Bellay, J., Kim, Y., Spear, E.D., Sevier, C.S., Ding, H., Koh, J.L.Y., Toufighi, K., Mostafavi, S., Prinz, J., St Onge, R.P., VanderSluis, B., Makhnevych, T., Vizeacoumar, F.J., Alizadeh, S., Bahr, S., Brost, R.L., Chen, Y., Cokol, M., Deshpande, R., Li, Z., Lin, Z.-Y., Liang, W., Marback, M., Paw, J., San Luis, B.-J., Shuteriqi, E., Tong, A.H.Y., van Dyk, N., Wallace, I.M., Whitney, J.A., Weirauch, M.T., Zhong, G., Zhu, H., Houry, W.A., Brudno, M., Ragibizadeh, S., Papp, B.A.Z., P a I, C., Roth, F.P., Giaever, G., Nislow, C., Troyanskaya, O.G., Bussey, H., Bader, G.D., Gingras, A.-C., Morris, Q.D., Kim, P.M., Kaiser, C.A., Myers, C.L., Andrews, B.J., Boone, C., 2010. The genetic landscape of a cell. Science 327, 425-431.

Costanzo, M., VanderSluis, B., Koch, E.N., Baryshnikova, A., Pons, C., Tan, G., Wang, W., Usaj, M., Hanchard, J., Lee, S.D., Pelechano, V., Styles, E.B., Billmann, M., van Leeuwen, J., van Dyk, N., Lin, Z.-Y., Kuzmin, E., Nelson, J., Piotrowski, J.S., Srikumar, T., Bahr, S., Chen, Y., Deshpande, R., Kurat, C.F., Li, S.C., Li, Z., Usaj, M.M., Okada, H., Pascoe, N., San Luis, B.-J., Sharifpoor, S., Shuteriqi, E., Simpkins, S.W., Snider, J., Suresh, H.G., Tan, Y., Zhu, H., Malod-Dognin, N., Janjić, V., Pržulj, N., Troyanskaya, O.G., Stagljar, I., Xia, T., Ohya, Y., Gingras, A.-C., Raught, B., Boutros, M., Steinmetz, L.M., Moore, C.L., Rosebrock, A.P., Caudy, A.A., Myers, C.L., Andrews, B., Boone, C., 2016. A global genetic interaction network maps a wiring diagram of cellular function. Science 353. doi:10.1126/science.aaf1420

Crow, T.J., 2011. 'The missing genes: what happened to the heritability of psychiatric disorders?'. Mol. Psychiatry 16, 362-364. doi:10.1038/mp.2010.92

Edwards, S.L., Beesley, J., French, J.D., Dunning, A.M., 2013. Beyond GWASs: illuminating the dark road from association to function. Am. J. Hum. Genet. 93, 779-797. doi:10.1016/j.ajhg.2013.10.012

Ehrenreich, I.M., Torabi, N., Jia, Y., Kent, J., Martis, S., Shapiro, J.A., Gresham, D., Caudy, A.A., Kruglyak, L., 2010. Dissection of genetically complex traits with extremely large pools of yeast segregants. Nature 464, 1039-1042. doi:10.1038/nature08923

Escalante-Chong, R., Savir, Y., Carroll, S.M., Ingraham, J.B., Wang, J., Marx, C.J., Springer, M., 2015. Galactose metabolic genes in yeast respond to a ratio of galactose and glucose. Proceedings of the National Academy of Sciences.

Friedman, A., Perrimon, N., 2006. A functional RNAi screen for regulators of receptor tyrosine kinase and ERK signalling. Nature 444, 230-234.

Giaever, G., Nislow, C., 2014. The yeast deletion collection: a decade of functional genomics. Genetics 197, 451-465.

Hindorff, L.A., Sethupathy, P., Junkins, H.A., Ramos, E.M., Mehta, J.P., Collins, F.S., Manolio, T.A., 2009. Potential etiologic and functional implications of genome-wide association loci for human diseases and traits. Proceedings of the National Academy of Sciences 106, 93629367. doi:10.1073/pnas.0903103106

Hou, J., Sigwalt, A., Fournier, T., Pflieger, D., Peter, J., de Montigny, J., Dunham, M.J., Schacherer, J., 2016. The Hidden Complexity of Mendelian Traits across Natural Yeast Populations. CellReports 16, 1106-1114. doi:10.1016/j.celrep.2016.06.048

Jonikas, M.C., Collins, S.R., Denic, V., Oh, E., Quan, E.M., Schmid, V., Weibezahn, J., Schwappach, B., Walter, P., Weissman, J.S., Schuldiner, M., 2009. Comprehensive characterization of genes required for protein folding in the endoplasmic reticulum. Science 323, 1693-1697. 
doi:10.1126/science.1167983

Jostins, L., Ripke, S., Weersma, R.K., Duerr, R.H., McGovern, D.P., Hui, K.Y., Lee, J.C., Schumm, L.P., Sharma, Y., Anderson, C.A., Essers, J., Mitrovic, M., Ning, K., Cleynen, I., Theatre, E., Spain, S.L., Raychaudhuri, S., Goyette, P., Wei, Z., Abraham, C., Achkar, J.-P., Ahmad, T., Amininejad, L., Ananthakrishnan, A.N., Andersen, V., Andrews, J.M., Baidoo, L., Balschun, T., Bampton, P.A., Bitton, A., Boucher, G., Brand, S., Büning, C., Cohain, A., Cichon, S., D'Amato, M., De Jong, D., Devaney, K.L., Dubinsky, M., Edwards, C., Ellinghaus, D., Ferguson, L.R., Franchimont, D., Fransen, K., Gearry, R., Georges, M., Gieger, C., Glas, J., Haritunians, T., Hart, A., Hawkey, C., Hedl, M., Hu, X., Karlsen, T.H., Kupcinskas, L., Kugathasan, S., Latiano, A., Laukens, D., Lawrance, I.C., Lees, C.W., Louis, E., Mahy, G., Mansfield, J., Morgan, A.R., Mowat, C., Newman, W., Palmieri, O., Ponsioen, C.Y., Potocnik, U., Prescott, N.J., Regueiro, M., Rotter, J.I., Russell, R.K., Sanderson, J.D., Sans, M., Satsangi, J., Schreiber, S., Simms, L.A., Sventoraityte, J., Targan, S.R., Taylor, K.D., Tremelling, M., Verspaget, H.W., De Vos, M., Wijmenga, C., Wilson, D.C., Winkelmann, J., Xavier, R.J., Zeissig, S., Zhang, B., Zhang, C.K., Zhao, H., International IBD Genetics Consortium (IIBDGC), Silverberg, M.S., Annese, V., Hakonarson, H., Brant, S.R., Radford-Smith, G., Mathew, C.G., Rioux, J.D., Schadt, E.E., Daly, M.J., Franke, A., Parkes, M., Vermeire, S., Barrett, J.C., Cho, J.H., 2012. Host-microbe interactions have shaped the genetic architecture of inflammatory bowel disease. Nature 491, 119-124. doi:10.1038/nature11582

Keren, L., Zackay, O., Lotan-Pompan, M., Barenholz, U., Dekel, E., Sasson, V., Aidelberg, G., Bren, A., Zeevi, D., Weinberger, A., Alon, U., Milo, R., Segal, E., 2013. Promoters maintain their relative activity levels under different growth conditions. Molecular Systems Biology 9, 701. doi:10.1038/msb.2013.59

Lango Allen, H., Estrada, K., Lettre, G., Berndt, S.I., Weedon, M.N., Rivadeneira, F., Willer, C.J., Jackson, A.U., Vedantam, S., Raychaudhuri, S., Ferreira, T., Wood, A.R., Weyant, R.J., Segr e, A.V., Speliotes, E.K., Wheeler, E., Soranzo, N., Park, J.-H., Yang, J., Gudbjartsson, D., HeardCosta, N.L., Randall, J.C., Qi, L., Vernon Smith, A., M a gi, R., Pastinen, T., Liang, L., Heid, I.M., Luan, J., Thorleifsson, G., Winkler, T.W., Goddard, M.E., Sin Lo, K., Palmer, C., Workalemahu, T., Aulchenko, Y.S., Johansson, A.S., Zillikens, M.C., Feitosa, M.F., Esko, T.O.N., Johnson, T., Ketkar, S., Kraft, P., Mangino, M., Prokopenko, I., Absher, D., Albrecht, E., Ernst, F., Glazer, N.L., Hayward, C., Hottenga, J.-J., Jacobs, K.B., Knowles, J.W., Kutalik, Z.A.N., Monda, K.L., Polasek, O., Preuss, M., Rayner, N.W., Robertson, N.R., Steinthorsdottir, V., Tyrer, J.P., Voight, B.F., Wiklund, F., Xu, J., Zhao, J.H., Nyholt, D.R., Pellikka, N., Perola, M., Perry, J.R.B., Surakka, I., Tammesoo, M.-L., Altmaier, E.L., Amin, N., Aspelund, T., Bhangale, T., Boucher, G., Chasman, D.I., Chen, C., Coin, L., Cooper, M.N., Dixon, A.L., Gibson, Q., Grundberg, E., Hao, K., Juhani Junttila, M., Kaplan, L.M., Kettunen, J., K o nig, I.R., Kwan, T., Lawrence, R.W., Levinson, D.F., Lorentzon, M., McKnight, B., Morris, A.P., M u ller, M., Suh Ngwa, J., Purcell, S., Rafelt, S., Salem, R.M., Salvi, E., Sanna, S., Shi, J., Sovio, U., Thompson, J.R., Turchin, M.C., Vandenput, L., Verlaan, D.J., Vitart, V., White, C.C., Ziegler, A., Almgren, P., Balmforth, A.J., Campbell, H., Citterio, L., De Grandi, A., Dominiczak, A., Duan, J., Elliott, P., Elosua, R., Eriksson, J.G., Freimer, N.B., Geus, E.J.C., Glorioso, N., Haiqing, S., Hartikainen, A.-L., Havulinna, A.S., Hicks, A.A., Hui, J., Igl, W., Illig, T., Jula, A., Kajantie, E., Kilpel a inen, T.O., Koiranen, M., Kolcic, I., Koskinen, S., Kovacs, P., Laitinen, J., Liu, J., Lokki, M.-L., Marusic, A., Maschio, A., Meitinger, T., Mulas, A., Par e, G., Parker, A.N., Peden, J.F., Petersmann, A., 
Pichler, I., Pietil a inen, K.H., Pouta, A., Ridderstr aa le, M., Rotter, J.I., Sambrook, J.G., Sanders, A.R., Schmidt, C.O., Sinisalo, J., Smit, J.H., Stringham, H.M., Bragi Walters, G., Widen, E., Wild, S.H., Willemsen, G., Zagato, L., Zgaga, L., Zitting, P., Alavere, H., Farrall, M., McArdle, W.L., Nelis, M., Peters, M.J., Ripatti, S., van Meurs, J.B.J., Aben, K.K., Ardlie, K.G., Beckmann, J.S., Beilby, J.P., Bergman, R.N., Bergmann, S., Collins, F.S., Cusi, D., Heijer, den, M., Eiriksdottir, G., Gejman, P.V., Hall, A.S., Hamsten, A., Huikuri, H.V., Iribarren, C., K a h o nen, M., Kaprio, J., Kathiresan, S., Kiemeney, L., Kocher, T., Launer, L.J., Lehtim a ki, T., Melander, O., Mosley, T.H., Musk, A.W., Nieminen, M.S., O’Donnell, C.J., Ohlsson, C., Oostra, B., Palmer, L.J., Raitakari, O., Ridker, P.M., Rioux, J.D., Rissanen, A., Rivolta, C., Schunkert, H., Shuldiner, A.R., Siscovick, D.S., Stumvoll, M., T o njes, A., Tuomilehto, J., van Ommen, G.-J., Viikari, J., Heath, A.C., Martin, N.G., Montgomery, G.W., Province, M.A., Kayser, M., Arnold, A.M., Atwood, L.D., Boerwinkle, E., Chanock, S.J., Deloukas, P., Gieger, C., Gr o nberg, H., Hall, P., Hattersley, A.T., Hengstenberg, C., Hoffman, W., Lathrop, G.M., Salomaa, V., Schreiber, S., Uda, M., Waterworth, D., Wright, A.F., Assimes, T.L., Barroso, I.E.S., Hofman, A., Mohlke, K.L., Boomsma, D.I., Caulfield, M.J., Cupples, L.A., Erdmann, J., Fox, C.S., Gudnason, V., Gyllensten, U., Harris, T.B., Hayes, R.B., Jarvelin, M.-R., Mooser, V., Munroe, P.B., Ouwehand, W.H., Penninx, B.W., Pramstaller, P.P., Quertermous, T., Rudan, I., Samani, N.J., Spector, T.D., V o Izke, H., Watkins, H., Wilson, J.F., Groop, L.C., Haritunians, T., Hu, F.B., Kaplan, R.C., Metspalu, A., North, K.E., Schlessinger, D., Wareham, N.J., Hunter, D.J., O'Connell, J.R., Strachan, D.P., Wichmann, H.E., Borecki, I.B., van Duijn, C.M., Schadt, E.E., Thorsteinsdottir, U., Peltonen, L., Uitterlinden, A.E.G., Visscher, P.M., Chatterjee, N., Loos, R.J.F., Boehnke, M., McCarthy, M.I., Ingelsson, E., Lindgren, C.M., Abecasis, G.C.C.A.R., Stefansson, K., Frayling, T.M., Hirschhorn, J.N., 2010. Hundreds of variants clustered in genomic loci and biological pathways affect human height. Nature 467, 832-838.

Lynch, M., Walsh, B., 1998. Genetics and Analysis of Quantitative Traits. Sinauer.

Maller, J., George, S., Purcell, S., Fagerness, J., Altshuler, D., Daly, M.J., Seddon, J.M., 2006. Common variation in three genes, including a noncoding variant in $\mathrm{CFH}$, strongly influences risk of age-related macular degeneration. Nature Genetics 38, 1055-1059. doi:10.1038/ng1873

Muller, H.J., 1932. Further studies on the nature and causes of gene mutations, in:. Presented at the Proceedings of the 6th International Congress of Genetics, pp. 213-255.

Nüsslein-Volhard, C., Wieschaus, E., 1980. Mutations affecting segment number and polarity in Drosophila. Nature 287, 795-801.

Okada, Y., Wu, D., Trynka, G., Raj, T., Terao, C., Ikari, K., Kochi, Y., Ohmura, K., Suzuki, A., Yoshida, S., Graham, R.R., Manoharan, A., Ortmann, W., Bhangale, T., Denny, J.C., Carroll, R.J., Eyler, A.E., Greenberg, J.D., Kremer, J.M., Pappas, D.A., Jiang, L., Yin, J., Ye, L., Su, D.-F., Yang, J., Xie, G., Keystone, E., Westra, H.-J., Esko, T., Metspalu, A., Zhou, X., Gupta, N., Mirel, D., Stahl, E.A., Diogo, D., Cui, J., Liao, K., Guo, M.H., Myouzen, K., Kawaguchi, T., Coenen, M.J.H., van Riel, P.L.C.M., van de Laar, M.A.F.J., Guchelaar, H.-J., Huizinga, T.W.J., Dieudé, P., Mariette, X., Bridges, S.L., Zhernakova, A., Toes, R.E.M., Tak, P.P., Miceli-Richard, C., Bang, S.-Y., Lee, H.-S., Martin, J., Gonzalez-Gay, M.A., Rodriguez-Rodriguez, L., Rantapää-Dahlqvist, S., Arlestig, L., Choi, H.K., Kamatani, Y., Galan, P., Lathrop, M., RACl consortium, GARNET consortium, Eyre, S., Bowes, J., Barton, A., de Vries, N., Moreland, L.W., Criswell, L.A., Karlson, E.W., Taniguchi, A., Yamada, R., Kubo, M., Liu, J.S., Bae, S.-C., Worthington, J., 
Padyukov, L., Klareskog, L., Gregersen, P.K., Raychaudhuri, S., Stranger, B.E., De Jager, P.L., Franke, L., Visscher, P.M., Brown, M.A., Yamanaka, H., Mimori, T., Takahashi, A., Xu, H., Behrens, T.W., Siminovitch, K.A., Momohara, S., Matsuda, F., Yamamoto, K., Plenge, R.M., 2014. Genetics of rheumatoid arthritis contributes to biology and drug discovery. Nature 506, 376-381. doi:10.1038/nature12873

Park, J.-H., Wacholder, S., Gail, M.H., Peters, U., Jacobs, K.B., Chanock, S.J., Chatterjee, N., 2010. Estimation of effect size distribution from genome-wide association studies and implications for future discoveries. Nat. Genet. 42, 570-575.

Pertea, M., Salzberg, S.L., 2010. Between a chicken and a grape: estimating the number of human genes. Genome Biology 11, 206. doi:10.1186/gb-2010-11-5-206

Regenberg, B., Grotkjær, T., Winther, O., Fausbøll, A., Åkesson, M., Bro, C., Hansen, L.K., Brunak, S., Nielsen, J., 2006. Growth-rate regulated genes have profound impact on interpretation of transcriptome profiling in Saccharomyces cerevisiae. Genome Biology 7, 1. doi:10.1186/gb-2006-7-11-r107

Sachidanandam, R., Weissman, D., Schmidt, S.C., Kakol, J.M., Stein, L.D., Marth, G., Sherry, S., Mullikin, J.C., Mortimore, B.J., Willey, D.L., Hunt, S.E., Cole, C.G., Coggill, P.C., Rice, C.M., Ning, Z., Rogers, J., Bentley, D.R., Kwok, P.Y., Mardis, E.R., Yeh, R.T., Schultz, B., Cook, L., Davenport, R., Dante, M., Fulton, L., Hillier, L., Waterston, R.H., McPherson, J.D., Gilman, B., Schaffner, S., Van Etten, W.J., Reich, D., Higgins, J., Daly, M.J., Blumenstiel, B., Baldwin, J., Stange-Thomann, N., Zody, M.C., Linton, L., Lander, E.S., Altshuler, D., International SNP Map Working Group, 2001. A map of human genome sequence variation containing 1.42 million single nucleotide polymorphisms. Nature 409, 928-933. doi:10.1038/35057149

Sherry, S.T., Ward, M.-H., Kholodov, M., Baker, J., Phan, L., Smigielski, E.M., Sirotkin, K., 2001. dbSNP: the NCBI database of genetic variation. Nucleic Acids Research 29, 308-311.

Slavov, N., Botstein, D., 2011. Coupling among growth rate response, metabolic cycle, and cell division cycle in yeast.

Tong, A.H.Y., Boone, C., 2006. Synthetic genetic array analysis in Saccharomyces cerevisiae. Methods Mol. Biol. 313, 171-192.

Wood, A.R., Esko, T., Yang, J., Vedantam, S., Pers, T.H., Gustafsson, S., Chu, A.Y., Estrada, K., Luan, J., Kutalik, Z., Amin, N., Buchkovich, M.L., Croteau-Chonka, D.C., Day, F.R., Duan, Y., Fall, T., Fehrmann, R., Ferreira, T., Jackson, A.U., Karjalainen, J., Lo, K.S., Locke, A.E., Mägi, R., Mihailov, E., Porcu, E., Randall, J.C., Scherag, A., Vinkhuyzen, A.A.E., Westra, H.-J., Winkler, T.W., Workalemahu, T., Zhao, J.H., Absher, D., Albrecht, E., Anderson, D., Baron, J., Beekman, M., Demirkan, A., Ehret, G.B., Feenstra, B., Feitosa, M.F., Fischer, K., Fraser, R.M., Goel, A., Gong, J., Justice, A.E., Kanoni, S., Kleber, M.E., Kristiansson, K., Lim, U., Lotay, V., Lui, J.C., Mangino, M., Leach, I.M., Medina-Gomez, C., Nalls, M.A., Nyholt, D.R., Palmer, C.D., Pasko, D., Pechlivanis, S., Prokopenko, I., Ried, J.S., Ripke, S., Shungin, D., Stančáková, A., Strawbridge, R.J., Sung, Y.J., Tanaka, T., Teumer, A., Trompet, S., van der Laan, S.W., van Setten, J., Van Vliet-Ostaptchouk, J.V., Wang, Z., Yengo, L., Zhang, W., Afzal, U., Ärnlöv, J., Arscott, G.M., Bandinelli, S., Barrett, A., Bellis, C., Bennett, A.J., Berne, C., Blüher, M., Bolton, J.L., Böttcher, Y., Boyd, H.A., Bruinenberg, M., Buckley, B.M., Buyske, S., Caspersen, I.H., Chines, P.S., Clarke, R., Claudi-Boehm, S., Cooper, M., Daw, E.W., De Jong, P.A., Deelen, J., Delgado, G., Denny, J.C., Dhonukshe-Rutten, R., Dimitriou, M., Doney, A.S.F., Dörr, M., Eklund, N., Eury, E., Folkersen, L., Garcia, M.E., Geller, F., Giedraitis, V., Go, A.S., Grallert, H., 
Grammer, T.B., Gräßler, J., Grönberg, H., de Groot, L.C.P.G.M., Groves, C.J., Haessler, J., Hall, P., Haller, T., Hallmans, G., Hannemann, A., Hartman, C.A., Hassinen, M., Hayward, C., Heard-Costa, N.L., Helmer, Q., Hemani, G., Henders, A.K., Hillege, H.L., Hlatky, M.A., Hoffmann, W., Hoffmann, P., Holmen, O., Houwing-Duistermaat, J.J., Illig, T., Isaacs, A., James, A.L., Jeff, J., Johansen, B., Johansson, Å., Jolley, J., Juliusdottir, T., Junttila, J., Kho, A.N., Kinnunen, L., Klopp, N., Kocher, T., Kratzer, W., Lichtner, P., Lind, L., Lindström, J., Lobbens, S., Lorentzon, M., Lu, Y., Lyssenko, V., Magnusson, P.K.E., Mahajan, A., Maillard, M., McArdle, W.L., McKenzie, C.A., McLachlan, S., McLaren, P.J., Menni, C., Merger, S., Milani, L., Moayyeri, A., Monda, K.L., Morken, M.A., Müller, G., Müller-Nurasyid, M., Musk, A.W., Narisu, N., Nauck, M., Nolte, I.M., Nöthen, M.M., Oozageer, L., Pilz, S., Rayner, N.W., Renstrom, F., Robertson, N.R., Rose, L.M., Roussel, R., Sanna, S., Scharnagl, H., Scholtens, S., Schumacher, F.R., Schunkert, H., Scott, R.A., Sehmi, J., Seufferlein, T., Shi, J., Silventoinen, K., Smit, J.H., Smith, A.V., Smolonska, J., Stanton, A.V., Stirrups, K., Stott, D.J., Stringham, H.M., Sundström, J., Swertz, M.A., Syvänen, A.-C., Tayo, B.O., Thorleifsson, G., Tyrer, J.P., van Dijk, S., van Schoor, N.M., van der Velde, N., van Heemst, D., van Oort, F.V.A., Vermeulen, S.H., Verweij, N., Vonk, J.M., Waite, L.L., Waldenberger, M., Wennauer, R., Wilkens, L.R., Willenborg, C., Wilsgaard, T., Wojczynski, M.K., Wong, A., Wright, A.F., Zhang, Q., Arveiler, D., Bakker, S.J.L., Beilby, J., Bergman, R.N., Bergmann, S., Biffar, R., Blangero, J., Boomsma, D.I., Bornstein, S.R., Bovet, P., Brambilla, P., Brown, M.J., Campbell, H., Caulfield, M.J., Chakravarti, A., Collins, R., Collins, F.S., Crawford, D.C., Cupples, L.A., Danesh, J., de Faire, U., Ruijter, den, H.M., Erbel, R., Erdmann, J., Eriksson, J.G., Farrall, M., Ferrannini, E., Ferrières, J., Ford, I., Forouhi, N.G., Forrester, T., Gansevoort, R.T., Gejman, P.V., Gieger, C., Golay, A., Gottesman, O., Gudnason, V., Gyllensten, U., Haas, D.W., Hall, A.S., Harris, T.B., Hattersley, A.T., Heath, A.C., Hengstenberg, C., Hicks, A.A., Hindorff, L.A., Hingorani, A.D., Hofman, A., Hovingh, G.K., Humphries, S.E., Hunt, S.C., Hypponen, E., Jacobs, K.B., Jarvelin, M.-R., Jousilahti, P., Jula, A.M., Kaprio, J., Kastelein, J.J.P., Kayser, M., Kee, F., KeinanenKiukaanniemi, S.M., Kiemeney, L.A., Kooner, J.S., Kooperberg, C., Koskinen, S., Kovacs, P., Kraja, A.T., Kumari, M., Kuusisto, J., Lakka, T.A., Langenberg, C., Le Marchand, L., Lehtimäki, T., Lupoli, S., Madden, P.A.F., Männistö, S., Manunta, P., Marette, A., Matise, T.C., McKnight, B., Meitinger, T., Moll, F.L., Montgomery, G.W., Morris, A.D., Morris, A.P., Murray, J.C., Nelis, M., Ohlsson, C., Oldehinkel, A.J., Ong, K.K., Ouwehand, W.H., Pasterkamp, G., Peters, A., Pramstaller, P.P., Price, J.F., Qi, L., Raitakari, O.T., Rankinen, T., Rao, D.C., Rice, T.K., Ritchie, M., Rudan, I., Salomaa, V., Samani, N.J., Saramies, J., Sarzynski, M.A., Schwarz, P.E.H., Sebert, S., Sever, P., Shuldiner, A.R., Sinisalo, J., Steinthorsdottir, V., Stolk, R.P., Tardif, J.-C., Tönjes, A., Tremblay, A., Tremoli, E., Virtamo, J., Vohl, M.-C., Amouyel, P., Asselbergs, F.W., Assimes, T.L., Bochud, M., Boehm, B.O., Boerwinkle, E., Bottinger, E.P., Bouchard, C., Cauchi, S., Chambers, J.C., Chanock, S.J., Cooper, R.S., de Bakker, P.I.W., Dedoussis, G., Ferrucci, L., Franks, P.W., Froguel, P., Groop, L.C., Haiman, C.A., Hamsten, A., Hayes, M.G., Hui, J., Hunter, D.J., Hveem, K., Jukema, J.W., Kaplan, R.C., Kivimaki, M., Kuh, D., Laakso, M., Liu, Y., Martin, N.G., März, W., Melbye, M., Moebus, S., Munroe, P.B., Njølstad, I., Oostra, B.A., Palmer, C.N.A., Pedersen, N.L., Perola, M., Pérusse, L., Peters, U., Powell, J.E., Power, C., Quertermous, T., Rauramaa, R., Reinmaa, E., Ridker, P.M., Rivadeneira, F., Rotter, J.I., Saaristo, T.E., Saleheen, D., Schlessinger, D., Slagboom, P.E., Snieder, H., Spector, T.D., Strauch, K., Stumvoll, M., Tuomilehto, J., Uusitupa, M., van der 
Harst, P., Völzke, H., Walker, M., Wareham, N.J., Watkins, H., Wichmann, H.E., Wilson, J.F., Zanen, P., Deloukas, P., Heid, I.M., Lindgren, C.M., Mohlke, K.L., Speliotes, E.K., Thorsteinsdottir, U., Barroso, I., Fox, C.S., North, K.E., Strachan, D.P., Beckmann, J.S., Berndt, S.I., Boehnke, M., Borecki, I.B., McCarthy, M.I., Metspalu, A., Stefansson, K., Uitterlinden, A.G., van Duijn, C.M., Franke, L., Willer, C.J., Price, A.L., Lettre, G., Loos, R.J.F., Weedon, M.N., Ingelsson, E., O’Connell, J.R., Abecasis, G.R., Chasman, D.I., Goddard, M.E., Visscher, P.M., Hirschhorn, J.N., Frayling, T.M., 2014. Defining the role of common variation in the genomic and biological architecture of adult human height. Nature Genetics 46, 1173-1186. doi:10.1038/ng.3097

Wykoff, D.D., Rizvi, A.H., Raser, J.M., Margolin, B., O'Shea, E.K., 2007. Positive feedback regulates switching of phosphate transporters in S. cerevisiae. MOLCEL 27, 1005-1013. doi:10.1016/j.molcel.2007.07.022

Yang, J., Bakshi, A., Zhu, Z., Hemani, G., Vinkhuyzen, A.A.E., Lee, S.H., Robinson, M.R., Perry, J.R.B., Nolte, I.M., Van Vliet-Ostaptchouk, J.V., Snieder, H., LifeLines Cohort Study, Esko, T., Milani, L., M a gi, R., Metspalu, A., Hamsten, A., Magnusson, P.K.E., Pedersen, N.L., Ingelsson, E., Soranzo, N., Keller, M.C., Wray, N.R., Goddard, M.E., Visscher, P.M., 2015. Genetic variance estimation with imputed variants finds negligible missing heritability for human height and body mass index. Nat. Genet. 47, 1114-1120.

Yang, J., Benyamin, B., McEvoy, B.P., Gordon, S., Henders, A.K., Nyholt, D.R., Madden, P.A., Heath, A.C., Martin, N.G., Montgomery, G.W., Goddard, M.E., Visscher, P.M., 2010. Common SNPs explain a large proportion of the heritability for human height. Nature Genetics 42, 565-569. doi:10.1038/ng.608

\section{Figure Legend}

\section{Figure 1. Genes outside of the canonical signaling pathways have the potential to} substantially influence pathway function

(A) A canonical pathway (red circles) can be modified by anywhere from a small number to large number of currently unidentified genes (green circles). (B) Regardless of the number of modifiers, the modifiers could range from having a weak to strong effect on the pathway (represented by arrow thickness). (C) If the number of modifiers is small (I) or if the effect size of the modifiers is small (II) the genetic architecture of the pathway will be centralized, i.e. a small number of genes will control the function of and variation in the pathway. If the 
698

699

700

701

702

703

704

705

706

707

708

709

710

711

712

713

714

715

716

717

718

719

number of modifiers is large and the effect size of the modifiers is sufficiently large (III) the genetic architecture will be distributed; i.e. a large number of genes will control the function of and variation in the pathway.

Figure 2. Quantitative genetic screen determines that a large number of genes quantitatively affects the yeast galactose response

(A) Galactose (Gal) activates while glucose (Glu) inhibits transcription from a GAL1

promoter YFP fusion. B) A mCherry expressing mutant strain (red) was co-culture with a wild-type reference strain (black); both strain contained the reporter construct from A.

Each well contained a distinct deletion mutant. (C) We defined two metrics to characterize the bimodal response of the GAL pathway. We defined the induced fraction (yellow area versus total area under the curve) as the percent of cells whose YFP expression level was above a threshold (black dotted line). We also defined the induction level as the mean YFP expression of all induced cells (green dotted line). (D) Mutant effect sizes for the induction level (D, left) and for induced fraction (D, right) are defined as the relative change in each metric between mutant (red) and the co-cultured wild-type reference strain (black). (E-F) Effect size distribution for two GAL traits. Effect sizes of all mutants were binned and plotted as a histogram (black bars). Mutant that passed a $0.5 \%$ false discovery rate cut-off were well fit with an exponential distribution using maximum likelihood estimation (dashed black line, $\mathrm{R}^{2} 0.96$ for each, see Method). The full distribution is parsimonious with a convolution of experimental noise and an exponential distribution (blue line is the average distribution of 100,000 simulations, $R^{2}=0.92-0.98$; gray shading is one standard deviation around the mean). 


\section{Figure 3. Pathway modifiers can significantly contribute to heritability}

721 (A) Methods to estimate the heritability explained by a set of deletion mutants. Genes were

722 sorted based on their effect size when deleted. The heritability was calculated as the sum of

723 the squares of the effect sizes for the top n genes compared to all genes. The heritability

724 (right) for the top 100 (red), 200 (blue), and 300 (green) mutant strains (left) is shown. (B-

725 C) The contribution to explained heritability, as calculated in A, from GAL genes (red) or all

726 genes (black) for induction level (B) and induced fraction (C).

\section{Figure 4. Core cellular processes affect quantitative traits}

728 (A) Venn diagram showing the overlap between genes that significantly affect each of our

729 four quantitative traits. Effect size for the unfolded protein response and growth rate in

730 rich media was determined by reanalyzing data from Jonikas et al. and Breslow et al.

731 (Breslow et al., 2008; Jonikas et al., 2009). Only genes that were assayed for all four traits

732 are included in the Venn diagram. (B) Identification of gene ontologies (GOs) that are

733 significantly clustered in the 4-D trait space. For each G0 the mean circular variance in the

734 4-D trait space was determined (Methods) and plotted against the corresponding number

735 of genes in that G0 (orange dots are significant, gray dots are not). To determine the $1 \%$

736 false discovery rate (FDR $<1 \%$, black line), gene names were permuted (10000 bootstraps)

737 before calculating the circular variance. GOs displayed in $\mathbf{C}$ and $\mathbf{D}$ are shown as squares. (C)

738 The average effect size vector for each significant GO in B projected into the 3-D induced

739 fraction-induction level-UPR response space. (D) Examples of GO with distinct spatial

740 clustering. The effect of gene deletion on the unfolded protein response vs. GAL induction

741 level (top) and on the GAL induced fraction vs. GAL induction level (bottom) was plotted 
742 for all genes from five different significant GOs from B (GO genes in color, all other genes in

743 gray). (Inset) Average mutant vector of GO.

744 Figure 5. Effects of protein synthesis perturbation on the phosphate response (PHO) 745 are distinct from the effects on the galactose response (GAL)

746 (A) Schematic of experiment to quantify the effects of perturbing protein synthesis on the

747 PHO response. A PH084 pr-YFP reporter was used to quantify PHO pathway activation in

748 single cells. Protein synthesis was perturbed by either (I) knocking out genes involved in

749 protein synthesis or (II) treating our wild-type strain with a titration of cycloheximide. (B-

750 D) The effects of perturbing protein synthesis are different between the GAL and PHO

751 response. Perturbation phenotypes were quantified by: 1) induced fraction, 2) induction

752 level and 3) for the PHO response, basal expression level. A set of 95 strains each deleted

753 for a gene involved protein synthesis (black dots) was assayed (GAL in B; PHO in C and D).

754 Cycloheximide (chx), a protein synthesis inhibitor, was added at 11 different

755 concentrations to a wild-type strain (green dots; green arrow denotes direction of

756 increasing chx concentration). Cycloheximide has a dose-dependent affect on both the GAL

757 and PHO response that phenocopies the effect of protein synthesis mutants. (E) The

758 expression distribution for two representative mutants, $r p l 16 a \Delta$ and $r p l 35 b \Delta$ in (red dots in

759 B-D). The GAL1pr-YFP (top) and PH084pr-YFP (bottom) distributions of rpl16aA and

760 rpl35bs mutants are shown (red), together with the co-cultured wild-type strain (black).

761 The induction level metric is denoted (dashed line). The induction level is not change in

762 PHO (bottom) while it is in GAL (top). 


\section{Figure 6 Effect size distribution estimated from gene deletions is informative for} more complex genetic scenarios

(A) In figure 3, heritability versus gene number was estimated assuming an allele frequency of 0.5 , exactly 1 SNP per gene, and the effect size distribution measured in figure 2. To simulate more complex biological scenarios, we sampled allele frequency from a Beta distribution, Beta $\left(f_{a}, f_{b}\right)$; number of SNPs from a Poisson distribution, Poisson $(\lambda)$; $\operatorname{simulated}$ hypomorphs by convolving the measured effect size distribution for amorphs with a Beta distribution, Beta $\left(\mathrm{S}_{\mathrm{a}}, \mathrm{S}_{\mathrm{b}}\right)$; and neomorphs by randomly sampling from the hypomorph

771 effect size distribution. The frequency of hypomorphs versus neomorphs was a constant, g,

772 for each simulation. The extremes and middle of the range of each distribution are shown

773 (red, blue, and green) (B) Comparison of the number of genes required to explain $80 \%$ of

774 the heritability in the experimental and simulated data. Simulate data was generated by

775 Latin hypercube sampling of the six parameters (1000 iterations; blue dots). The fraction of 776 neomorphs (g) had the largest affect on the model. To examine the effect of the rest of

777 parameters, g was set to 5\% (vertical red dashed line), and Latin hypercube sampling was

778 used was used to scan the remaining five parameter space 1000 times (red dots). 
error of each assay in Table S4 was determined as the standard deviation of the differences of replicate measurements for identical strains (see Supplemental Information for details). The effect sizes were compared to measurement noise distribution, $\sim \boldsymbol{N}(0$, measurement noise), to assign p-values for mutants. False discovery rates (FDR) were used to correct for the multiple hypothesis test problem. Significant mutants were defined as ones with FDR less than $0.5 \%$.

Plasmid and strain construction. We constructed a plasmid containing the GAL1 promoter

790 driving YFP with a Zeocin resistance marker all flanked by regions that are homologous to the

$791 \mathrm{HO}$ locus (A65V). This plasmid was digested with Not1 and transformed into the parental SGA

792 strain (B56Y, MATx ura3 $\Delta$ leu2 $\Delta$ his3 $\Delta$ met15 $\Delta$ can1 $\Delta:$ :ste2pr-spHIS5 lyp1 $\Delta:: S t e 3 p r-L E U 2$ LYS2+

793 cyh2)(Tong and Boone, 2006) to construct a base strain (D62Y), which was used to create both

794 query and reference strains used in the GAL screen. Query strains (library SLL14) were

795 constructed using the SGA techniques(Tong and Boone, 2006) on the deletion collection and

796 base strain D62Y. A reference strain (F59Y) was constructed by a second transformation with a

797 TDH3pr-mCherry construct. The PHO84 promoter driving YFP reporter (E40B) was constructed

798 using similar method by using PHO84pr PCR-ed from FY4 (using primer

CGTACGCTGCAGGTCGACGGATCCCGTTTTTTTACCGTTTAGTAGACAG and

800 TAATTCTTCACCTTTAGACATTTTGTTATTAATTAATTGGATTGTATTCGTGGAGTTTTG) instead of the

801 GAL1 promoter. The resulting PHO library (SLL15) and reference strain (I32Y) were used in the 802 PHO screen.

803 Galactose induction assay. Mutant strains from the deletion library that contains GAL1pr-YFP 804 reporter and the corresponding reference strain were pinned onto YEPD agar plate before 
805 being inoculated into synthetic complete $2 \%$ raffinose medium to allow growth till saturation.

806 Mutants and the reference strain were pinned together into $150 \mu$ of fresh raffinose medium

807 and grown for another seven hours, before being inoculated into $150 \mathrm{ul}$ of synthetic complete

$808 \quad 0.2 \%$ glucose and $0.3 \%$ galactose. After induction for eight hours, $10 \mathrm{ul}$ of cultures were

809 analyzed by flow cytometry LSRII with HTS. Each plate ran for 20 minutes on the instrument.

810 To ensure that all mutants underwent roughly the same induction time, no more than four

811 plates were inoculated at a time. The induction level and induced fraction trait were based on

812 measurements from two biological replicates in two separate days. Data were analyzed using a

813 Matlab script (for representative raw data, see Figure S6).

814 Phosphate starvation induction assay. Mutant strains from the library that contain the

815 PHO84pr-YFP reporter and the corresponding reference strain were pinned on YEPD plate

816 before being inoculated into synthetic glucose medium (SD). Mutants and the reference strain

817 were then co-cultured in SD for 12 hours before washing in water twice and transferred into

818 induction medium - synthetic glucose medium supplemented with $200 \mu \mathrm{M}$ of $\mathrm{K}_{2} \mathrm{HPO}_{4}$. Medium

819 recipe is from Wykoff et al. (Wykoff et al., 2007). Cultures were analyzed by a Stratedigm

820 S1000EX cytometer cytometry. The three PHO traits were based on measurements from two

821 biological replicates in two separate days. Data was analyzed using Matlab scripts.

822 Fitting the effect size distribution. As the measured effects of most strains are close to

823 measurement error, we first analyzed the effect size distribution of strains with significant

824 measured effect sizes (FDR<0.5\%). Mutant effect sizes were binned and fitted to exponential 
825 distributions. The only fitting parameter is the scale of the exponential distribution, which was

826 estimated by maximizing the following log-likelihood function.

$$
\log L=\sum_{\text {significant genes }} \log \left(P\left(E S_{i} \mid \theta\right)\right)
$$

827, where $E S_{i}$ is the effect size of the $i^{\text {th }}$ significant gene, and $\theta$ is the the scale of the exponential 828 distribution. The probability distribution is an exponential distribution defined over a range of 829 effect size, i.e.:

$$
P(x \mid \theta)=\frac{\frac{1}{\theta} \int_{x_{\min }}^{\infty} \exp \left(-\frac{x}{\theta}\right) d x}{\exp \left(-\frac{x_{\min }}{\theta}\right)}
$$

830 Parameters that maximize the likelihood of measurements were used for Figure 2. The fitted 831 exponential distribution was extrapolated into the small effect size region to estimate the 832 number of genes that are likely to follow the distribution. As a parsimonious model to explain 833 our effect size measurements for four traits, we assumed the rest of mutants to have effect 834 sizes as zero. Using this model, we predicted the expected effect size measurement distribution 835 by convolving the true effect size distribution with the measurement noise of each assay (solid 836 blue line in Figure 2). This distribution was then randomly sampled in 10,000 simulations and 837 the standard deviation of the simulation was used as the confident zone of our estimation.

838 Extrapolate the number of genes that affect quantitative traits to human traits. The number

839 of significant genes were corrected by a factor determined by the gene number ratio between 840 known human genes and screened yeast genes. The number of human genes is estimated as 
84122,500 (Pertea and Salzberg, 2010). The number of screened yeast genes was determined as

842 the number of genes that passed quality control.

843 Simulation of potential biases from the study of amorphs. In our model, we defined the

844 explained heritability as the total explained heritability by all SNPs that affect each gene. As

845 described in the main text, we simulated the number of SNPs that affect each gene as a Poisson

846 distribution. The allele frequency and relative effect size are modeled using beta distribution.

847 Gain-of-function SNPs were modeled by re-assigning effect sizes of a fraction of all SNPs by

848 randomly sampling from the effect size distribution of all SNPs. In our Latin hypercube sampling,

849 parameters in the two beta distributions ranged from 0.5 to 9 , the fraction of gain-of-function

850 SNPs ranged from 0 to 50\%, and the average number of SNP per gene ranged from 1 to 100.

851 The heritability of each SNP is modeled as $2 * S^{2 *} f^{*}(1-f)$, where $S$ is effect size and $f$ is allele

852 frequency. Measured knockout effect size on induced level is used in the model as complete

853 loss-of-function effects. The code used for this simulation is available at Dryad.

854 Gene Ontology analysis. Genes that are significant for all four traits (FDR $<0.5 \%)$ were used as a

855 hit list; all the genes that passed quality control were used as a background list. Gene Ontology

856 analyses were done using GO TermFinder (Boyle et al., 2004).

857 Spatial clustering algorithm. Each gene was represented a 4-dimensional effect size vector

858 using the effect size measured for each of the four yeast traits. Since different traits have

859 different units, we normalized each dimension of the effect size vectors by its scale, which is

860 defined as the root mean square of the effect sizes of all the genes that significantly affect that

861 trait. For any gene set, we determined the similarity of their effects on four traits by 1) filtering 
862 out all genes that are not significant to any of our traits; 2 ) calculate the circular mean of the

863 normalized effect size vectors (e) as: $\left.R=\sum \vec{e} /|\vec{e}| ; 3\right)$ calculate the circular deviation as

$864 \operatorname{Var}=1-R$. To determine the significance of this, we repeated the calculation 10,000 times

865 after randomizing the gene names. Gene Ontologies that have at least five genes significant for

866 any of the four traits were analyzed using the method above. Significantly clustered processes

867 were defined as FDR $<0.01$.

868 Cycloheximide effect on GAL and PHO. Cycloheximide was purchased from Sigma (C7698).

869 Cycloheximide was added directly to the induction media and this was the only change in the

870 protocol from strains that were not exposed to cycloheximide. Cells were grown in a two-fold

871 dilution series of cycloheximide with the highest concentration of cycloheximide being $20 \mu \mathrm{g} / \mathrm{ml}$.

872 Cycloheximide effects in Figure 5 were based on at least three biological replicates.

873 Data and code Availability. All codes and raw data will be made available on Dryad. 

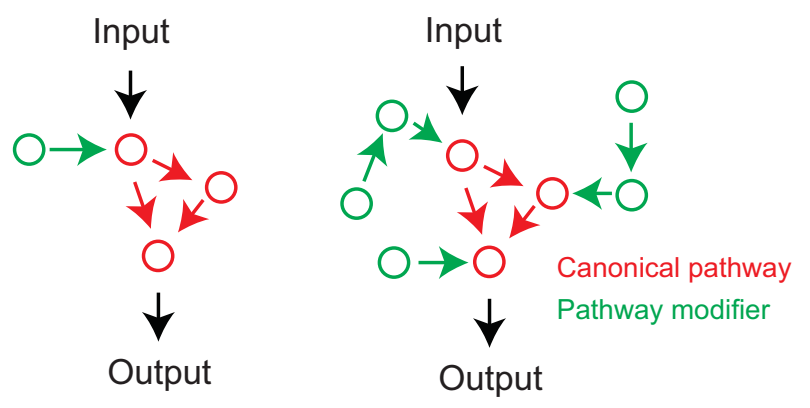

Few

Number of modifiers

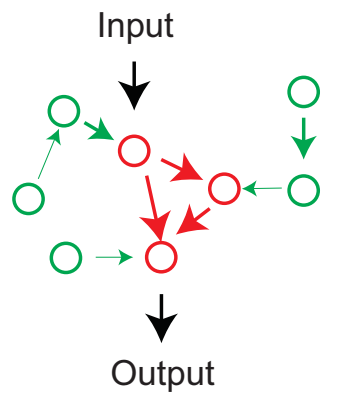

Weak

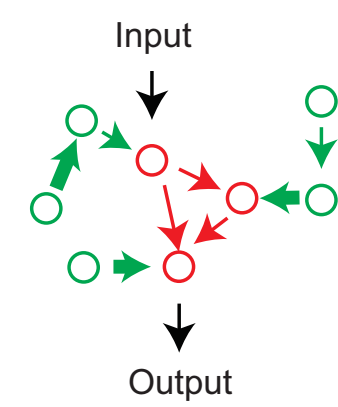

Interaction strength

$\longrightarrow$ Weak

$\Rightarrow$ Strong

$\longrightarrow$ Strong

C

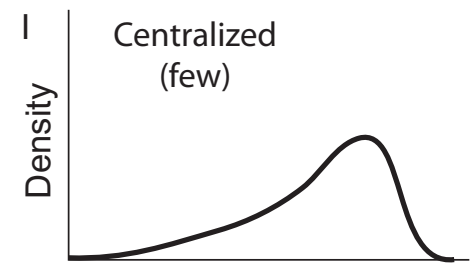

Effect size of genes

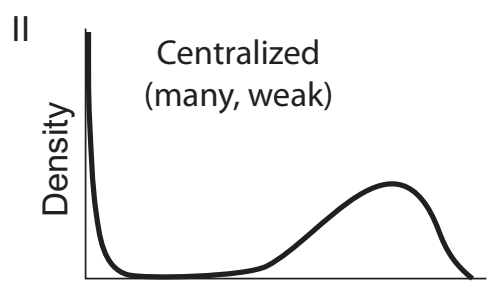

Effect size of genes

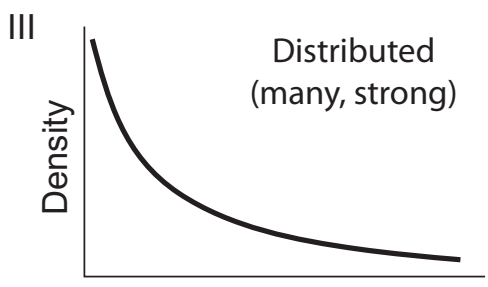

Effect size of genes 
A

B

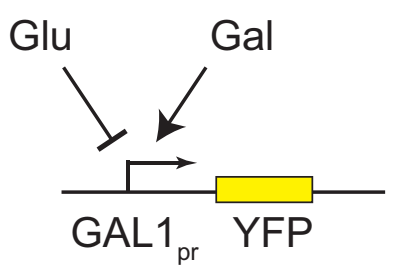

C Metric definition Threshold

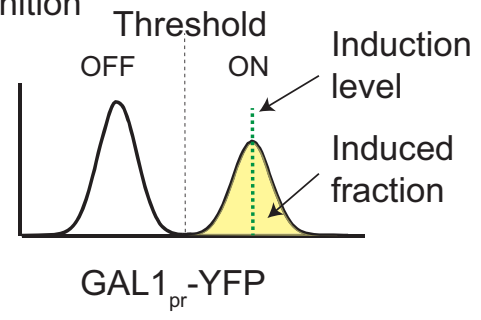

D Effect size definition

Co-culture:

Wild-type reference

Gene knockout strain

$0.2 \%$ Glucose + $0.3 \%$ Galactose
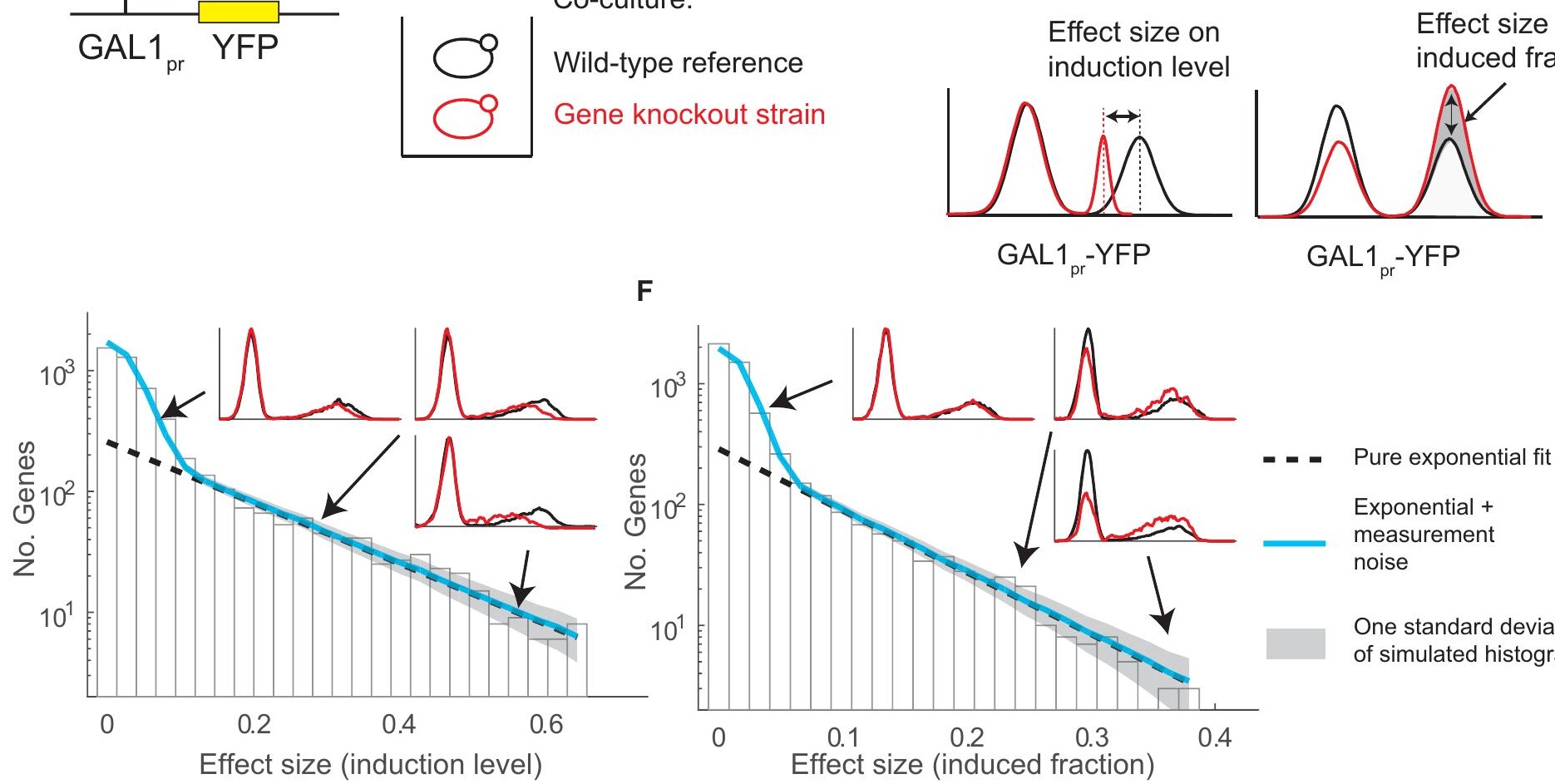

F

Induce in

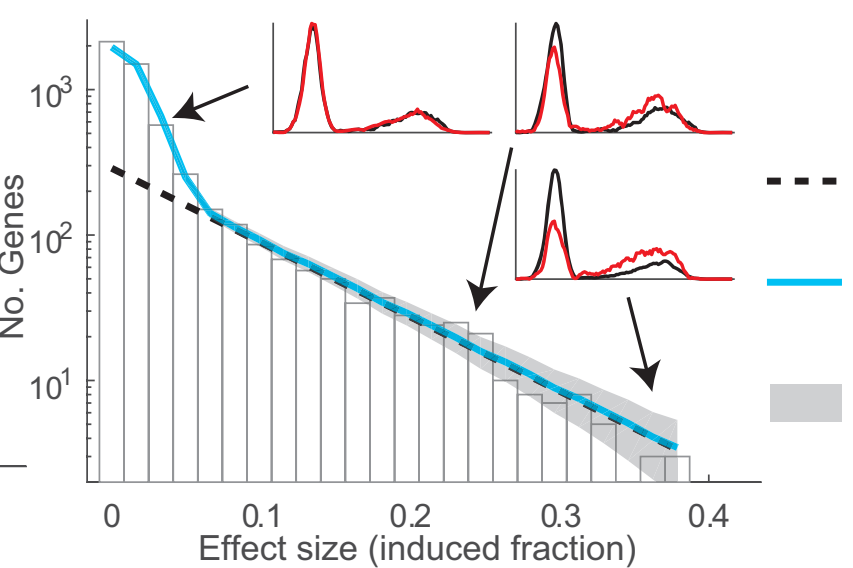

Pure exponential fit

Exponential +

measurement

noise

One standard deviation of simulated histogram 

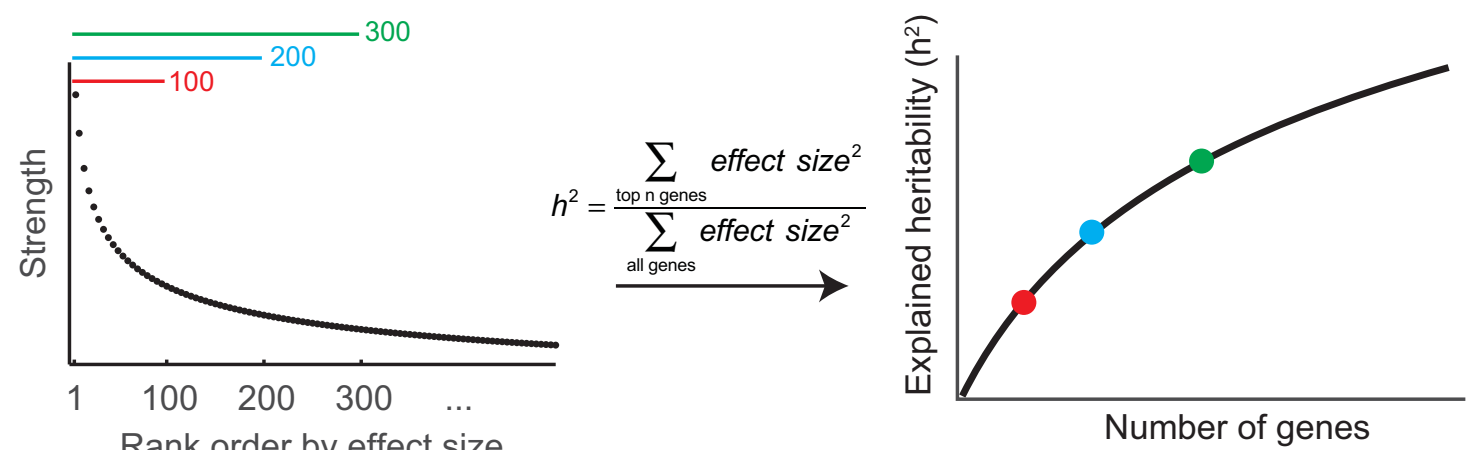

B

C
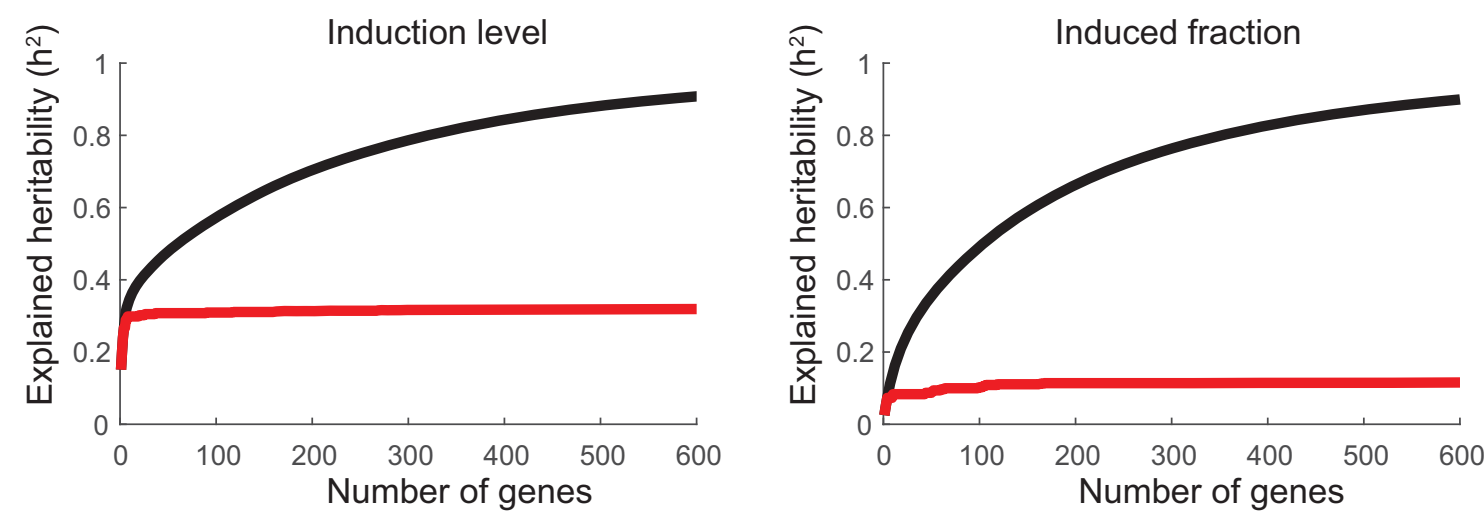

All genes

- Glu/Gal genes 

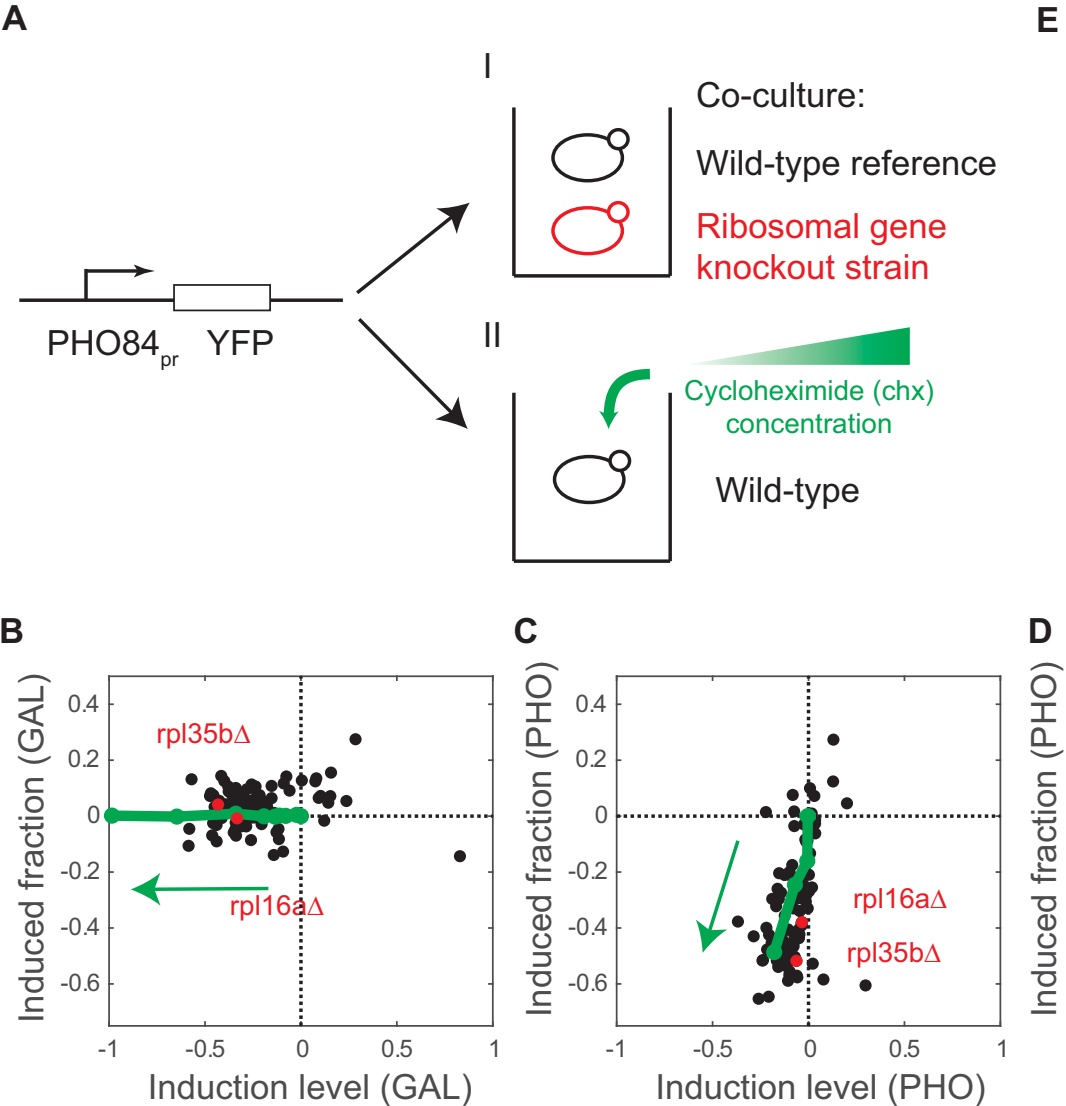

Co-culture:

Wild-type reference

Ribosomal gene

knockout strain
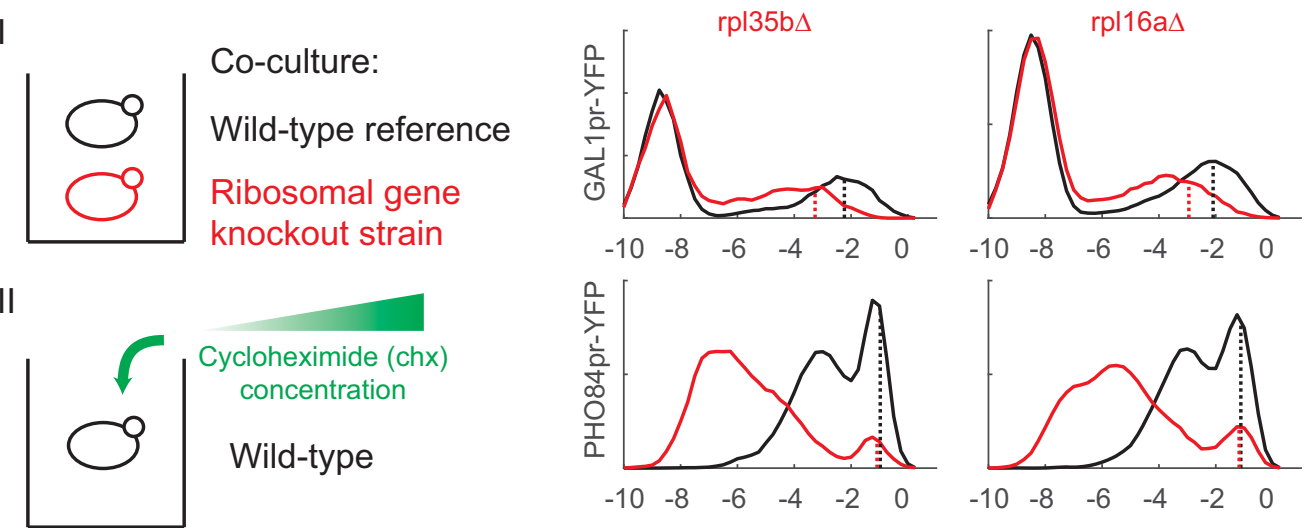

C
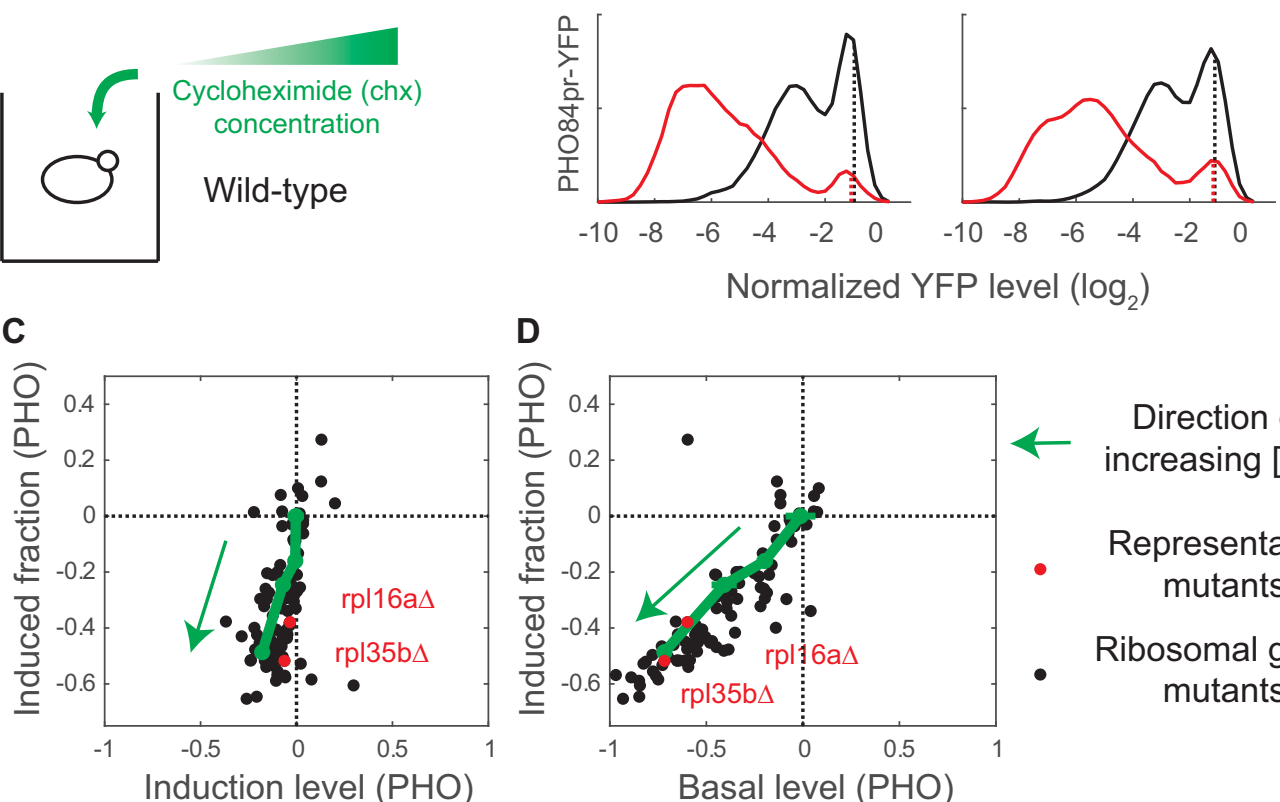

D

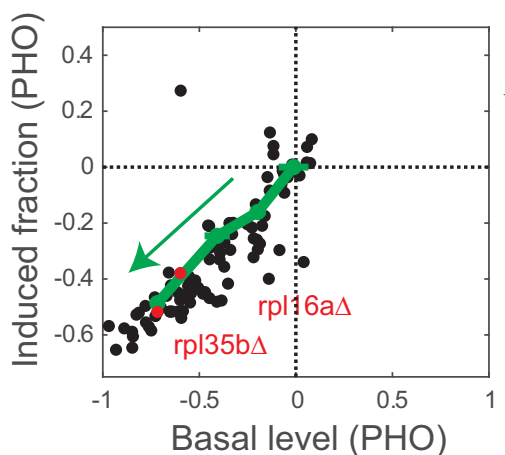

Direction of increasing [chx]

Representative mutants

Ribosomal gene mutants 
Allele frequency No. of allele
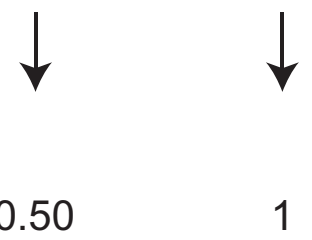

0.50

Effect size

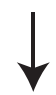

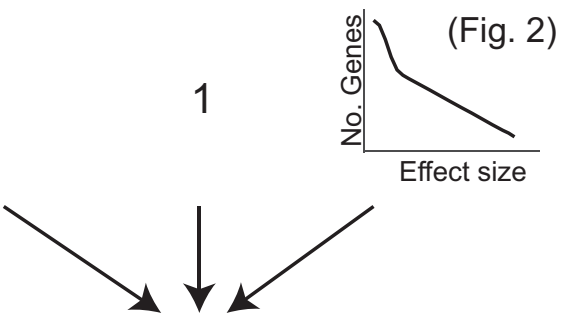

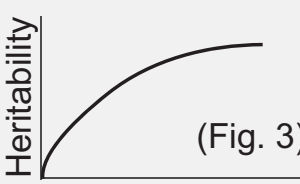

Number of genes
Allele frequency
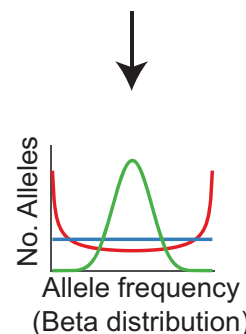

(Beta distribution)
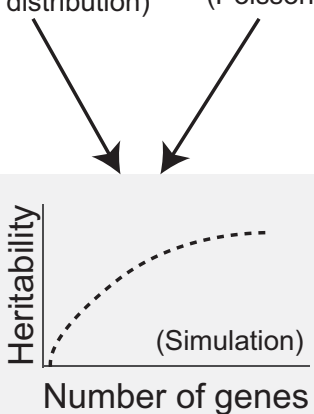

No. of allele
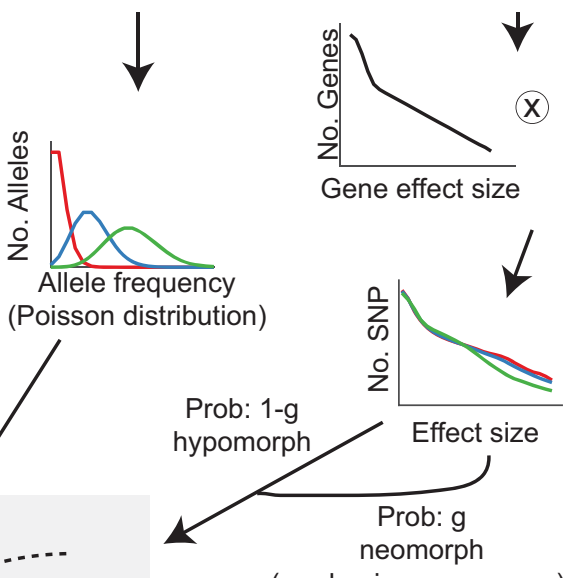

(randomize gene name)

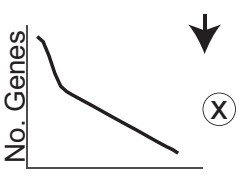

Gene effect size

$\sqrt{1}$

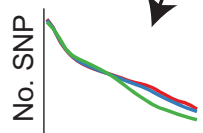

Relative strength, SNP/Gene

(Beta distribution)
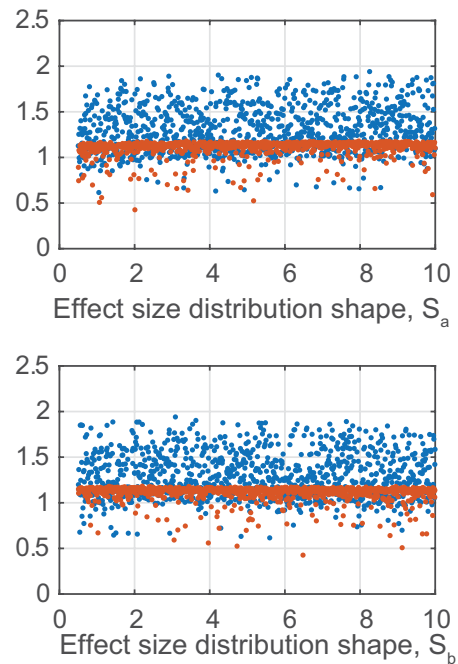
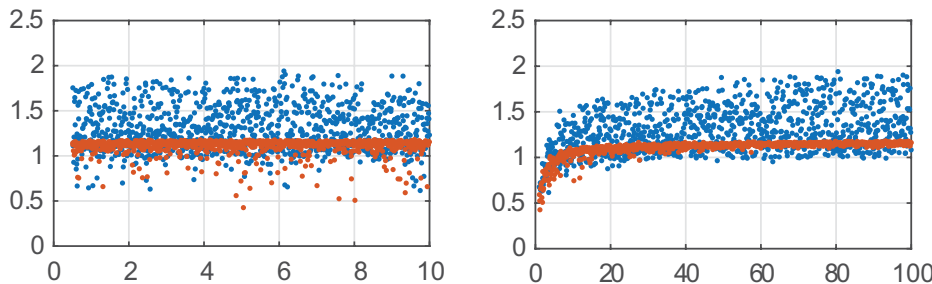

Allele frequency distribution shape, $f_{a}$ Average number of SNPs per gene, $\lambda$
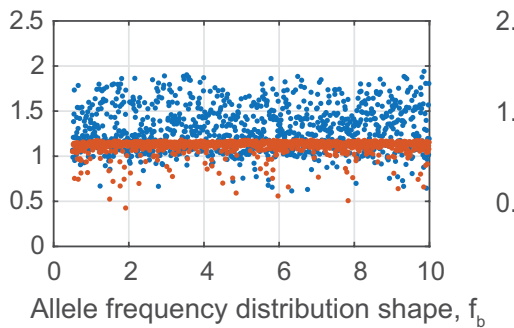

\footnotetext{
Allele frequency distribution shape, $\mathrm{f}_{b} \quad$ Probability of gain-of-function SNP, $g$
}

Latin hypercube sampling for all six parameters

Latin hypercube sampling with fixed neomorph probability 


\section{Table of contents}

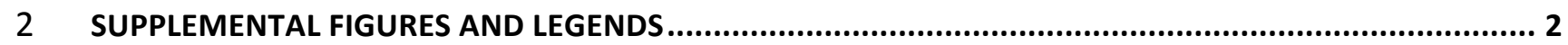

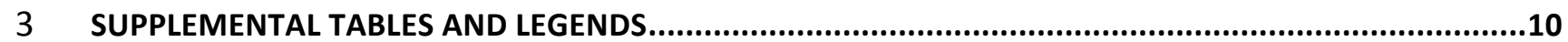

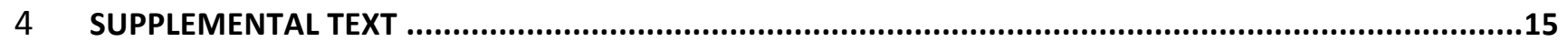

5 RE-ANALYSIS OF PREVIOUS QUANTITATIVE SCREENING USING YEAST DELETION COLLECTIONS ................................15

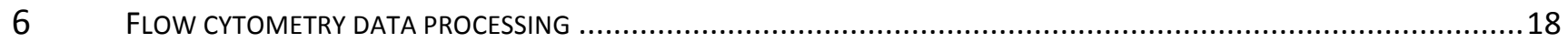

7 PRINCIPAL COMPONENT ANALYSIS ON REPORTER EXPRESSION DISTRIBUTION OF THE ENTIRE DELETION COLLECTION ......19

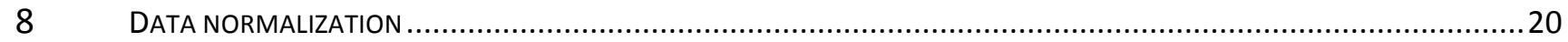

9 ESTIMATE THE NUMBER OF GENES THAT AFFECT YEAST QUANTITATIVE TRAITS ...................................................21

10 COMPARE THE NUMBER OF DETECTED MUTANTS BY USING INDUCED FRACTION AND INDUCTION LEVEL VS. AVERAGE

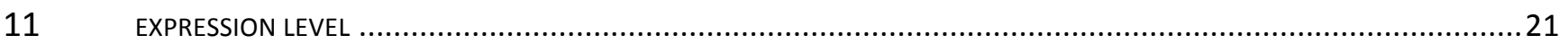

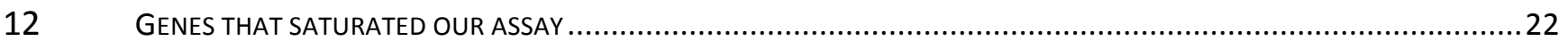

13 OVERLAPPING AMONG GENES THAT ARE SIGNIFICANT FOR EACH OF THE FOUR STUDIED TRAITS................................23

14 COMPARE THE EFFECTS ON GAL AND PHO RESPONSE BY DELETING GENES INVOLVED IN PROTEIN SYNTHESIS...............23

15 CANONICAL GENES INVOLVED IN GALACTOSE SIGNALING AND UNFOLDED PROTEIN RESPONSE................................24

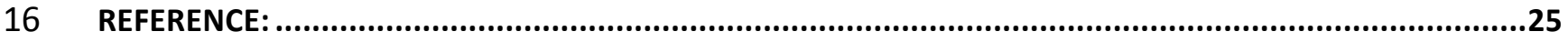


Supplemental figures and legends
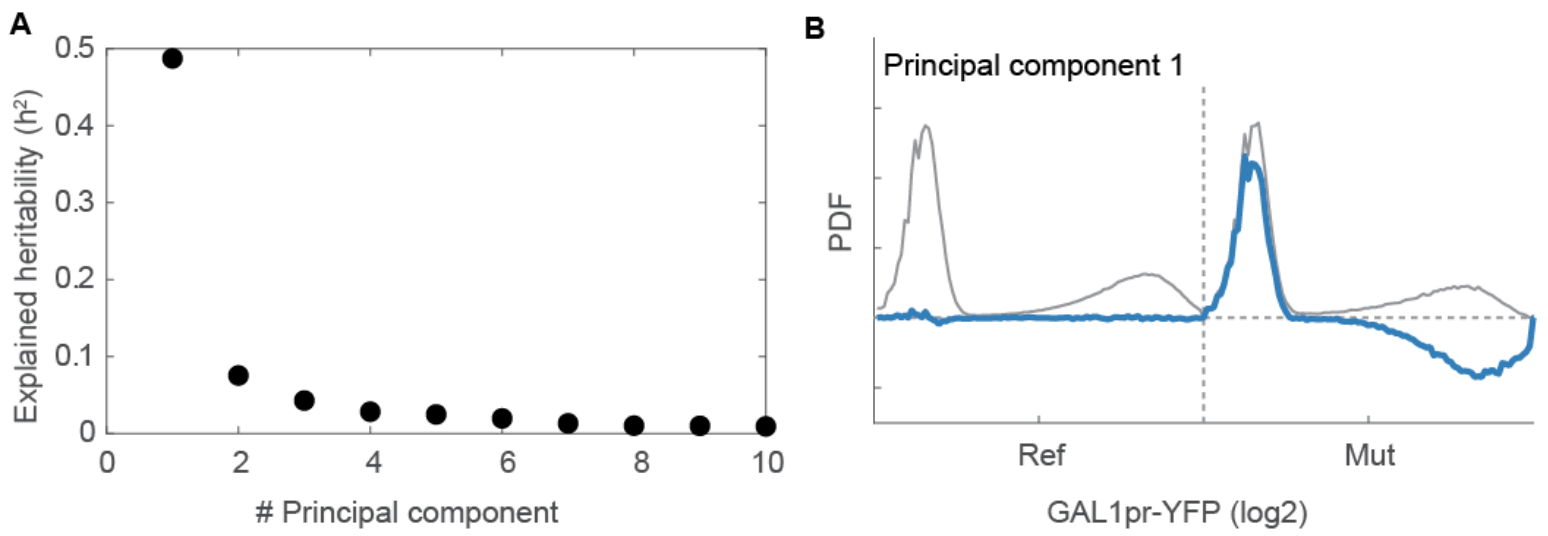

C

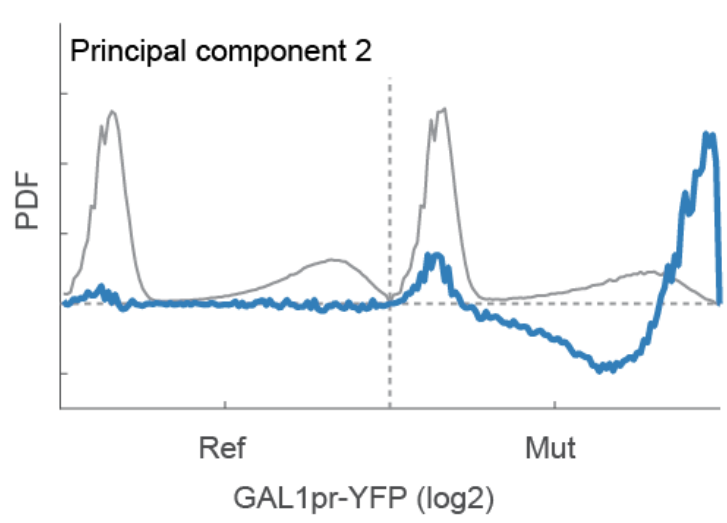

GAL1pr-YFP (log2)

Figure S1. Determining modes of response with principal component analysis (Figure S1.

\section{Related to Figure 2)}

After data segmentation, histograms of GAL1pr-YFP for the mutant and reference strain for each sample were normalized, concatenated, and then analyzed using principal component analysis. (A) The fraction of variation explained by the first ten principal components. (B-C)

25 Effects on GAL1pr-YFP distribution by the top two principal components. The average GAL1pr-

26 YFP distribution of all reference and mutant strains are concatenated (gray). The principal

27 component (blue) from the PCA analysis is the deviation from this average profile due to 
bioRxiv preprint doi: https://doi.org/10.1101/126409; this version posted April 11, 2017. The copyright holder for this preprint (which was not certified by peer review) is the author/funder, who has granted bioRxiv a license to display the preprint in perpetuity. It is made available under aCC-BY-NC-ND 4.0 International license.

29 strain. Note that the first two principal components correspond to biological properties, i.e. the 30 induced fraction and induction level. 

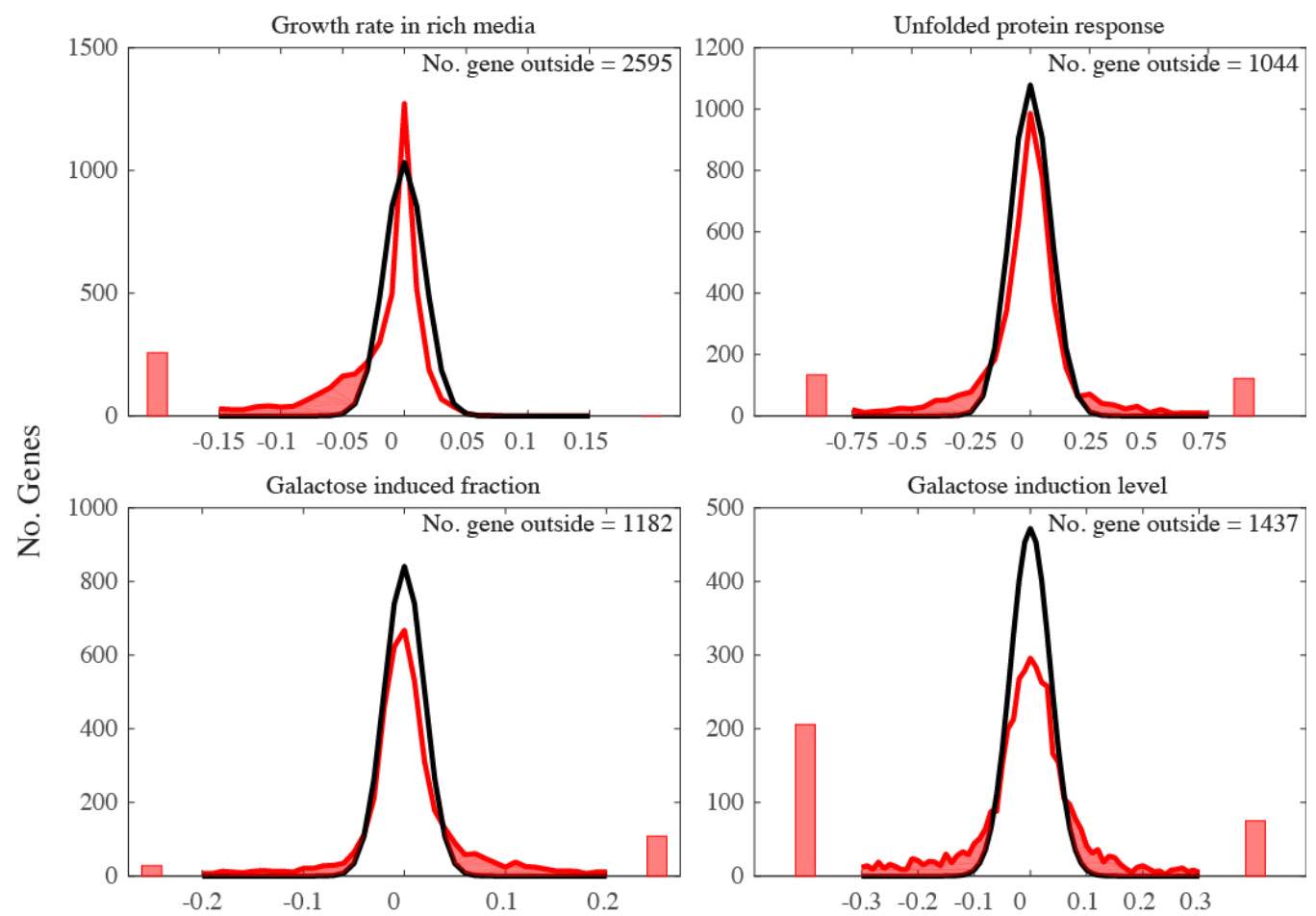

Effect size

Figure S2. Effect size distribution versus measurement noise for four traits (Figure S2. Related

34 As many mutants have effect sizes that are close to or smaller than average measurement noise,

35 the total number of genes that affects each quantitative trait was estimated by comparing the

36 measured effect size distribution (red) and measurement noise effect size distribution (black).

37 The measurement noise effect size distribution is the distribution of measurement noises

39 from the number of genes in the shaded region. 
A

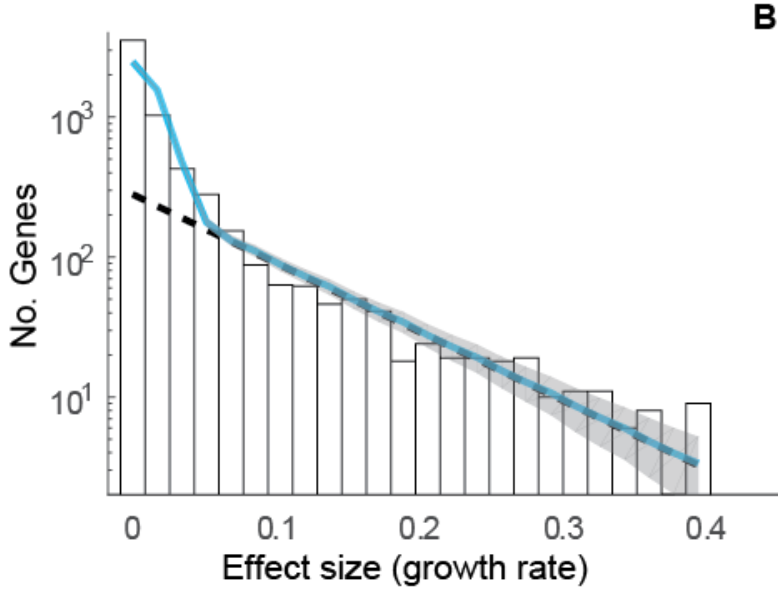

C

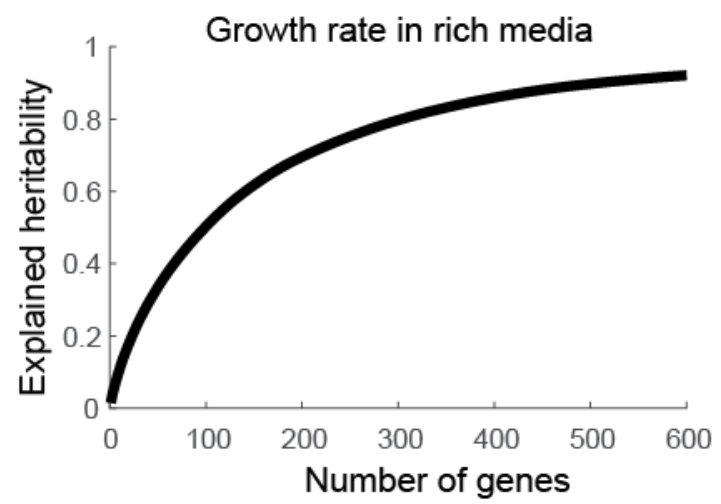

B
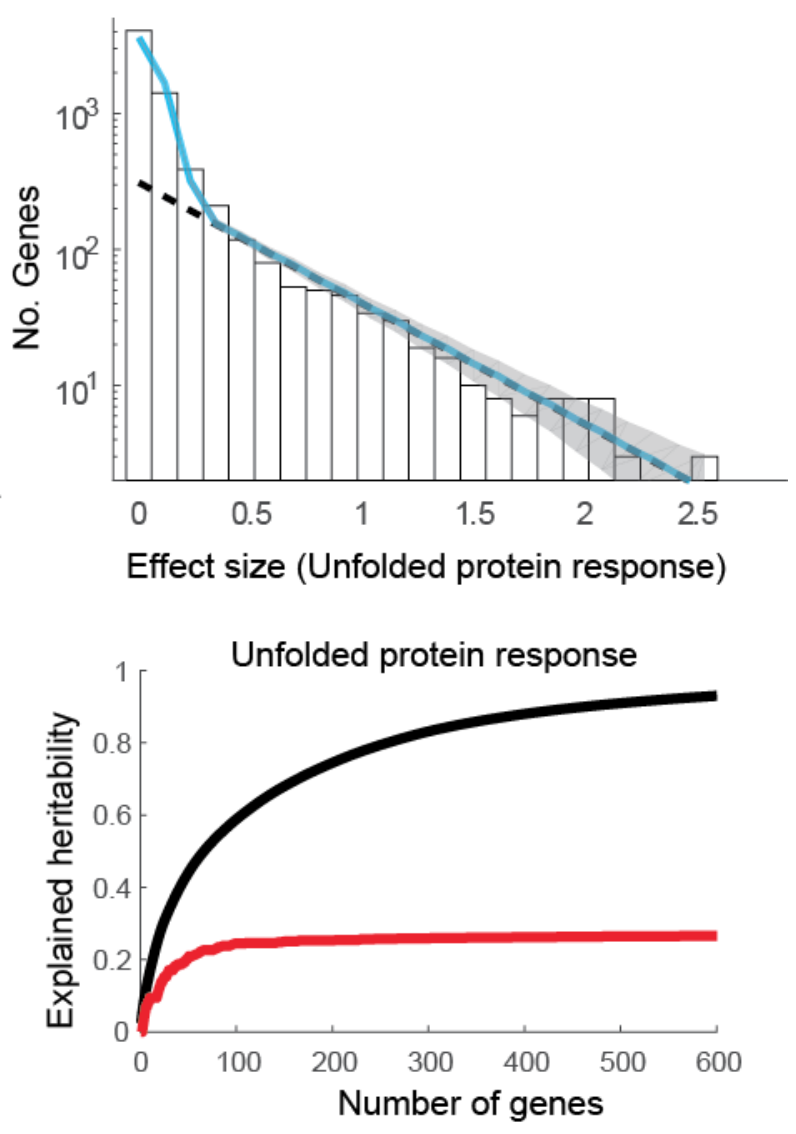

Figure S3. Reanalysis of two screens confirms that a large number of genes quantitatively affect yeast galactose response (Figure S3. Related to Figure 2; Figure 3)

Data from two deletion studies (Breslow et al., 2008; Jonikas et al., 2009), one on growth rate in rich medium and one on the unfolded protein response (UPR), were reanalyzed. Both the effect size distribution (A-B) and explained heritability (C-D) were calculated as in Figure $\mathbf{2}$ and $\mathbf{3}$. Fit of the significant genes to an exponential (dashed line) has an $\mathrm{R}^{\wedge} 2$ of 0.91 for growth rate $(\mathbf{A})$ and 0.94 for UPR (B). The fit of the full data to an exponential plus noise had an $R^{\wedge} 2$ of 9.2 (A) and 
A

Growth rate-dependent model

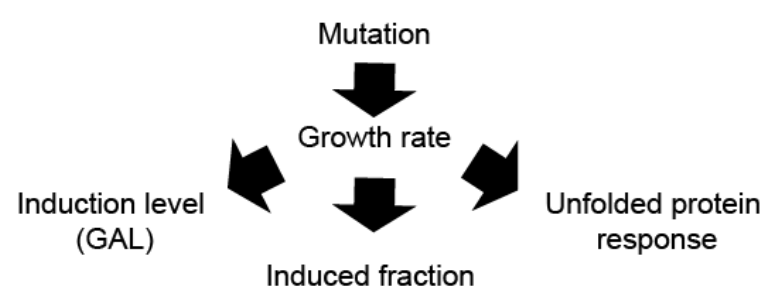

(GAL)
Growth rate-independent model

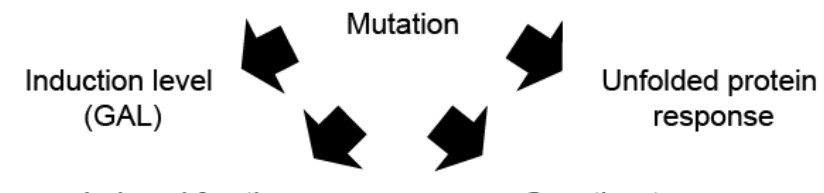

Induced fraction

(GAL)
Growth rate
B

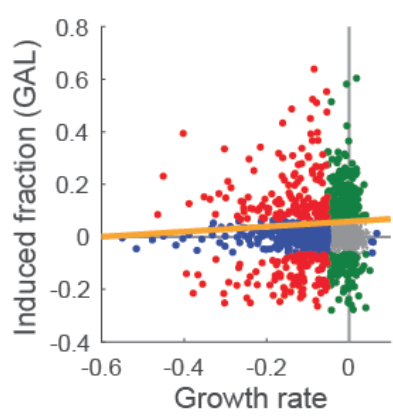

C

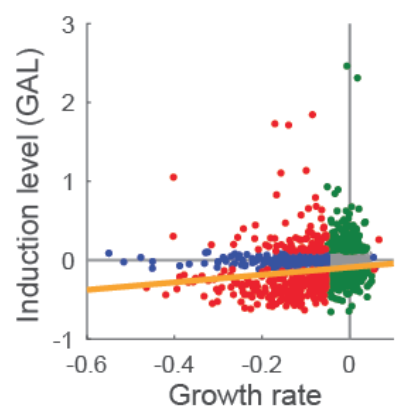

$\mathrm{D}$

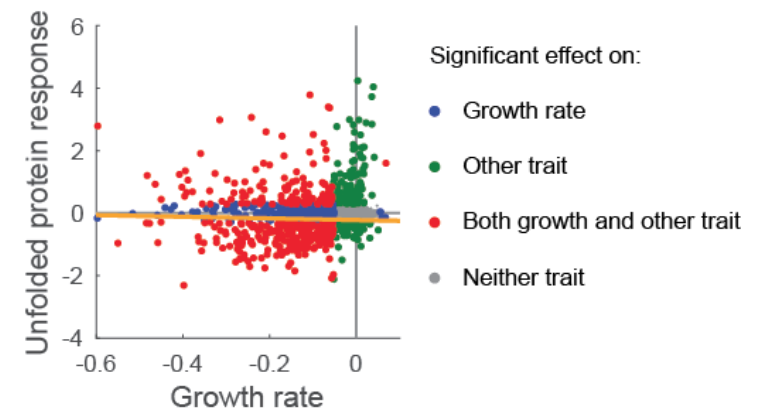
yeast GAL response and unfolded protein response (Figure S4. Related to Figure 4)

53 (A) Two alternative models of how quantitative traits can be affected by gene deletion. In the

54 growth rate-dependent model (left), mutants affect growth rate that in turn affects other traits.

55 In the growth rate-independent model (right), mutants directly affect quantitative traits

56 including growth rate. These two models can be distinguished by determining whether mutant

57 effects on growth rate and other traits are correlated. (B-D) Mutant phenotypes for the

59 against the growth rate data reported by Breslow et al. Mutants were segmented into four quadrants based on whether the mutant had a significant effect (based on $0.5 \%$ FDR cut-off) on

61 growth rate and non-growth rate trait: growth rate (blue), other non-growth rate trait (green), 
bioRxiv preprint doi: https://doi.org/10.1101/126409; this version posted April 11, 2017. The copyright holder for this preprint (which was not certified by peer review) is the author/funder, who has granted bioRxiv a license to display the preprint in perpetuity. It is made available under aCC-BY-NC-ND 4.0 International license.

62 both (red), neither (gray). A linear fit of the points that are significant for both traits (red) is

63 plotted (orange line). 


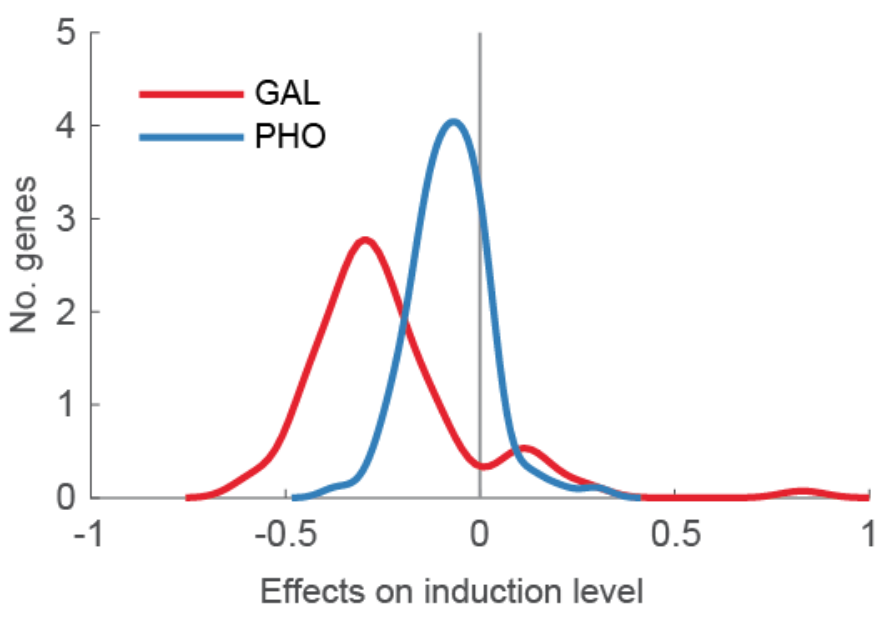

65 Figure S5. The difference of effects on GAL and PHO response by deleting genes involved in

66 protein synthesis (Figure S5. Related to Figure 5)

67 For each of the 95 mutants we tested that are involved in protein synthesis, the mutant effects

68 on the induction level were quantified for the PHO (blue) and GAL (red) responses. The effect

69 size distribution was smoothened with kernel smoothing with a bandwidth of 0.05 . The two

70 distributions are extremely unlike to have results from noise in a single distribution ( $p$-value

$713^{*} 10^{-10}$, two-tailed t-test). The magnitude of the average difference in effect size between the

72 two distributions is 3 fold. 


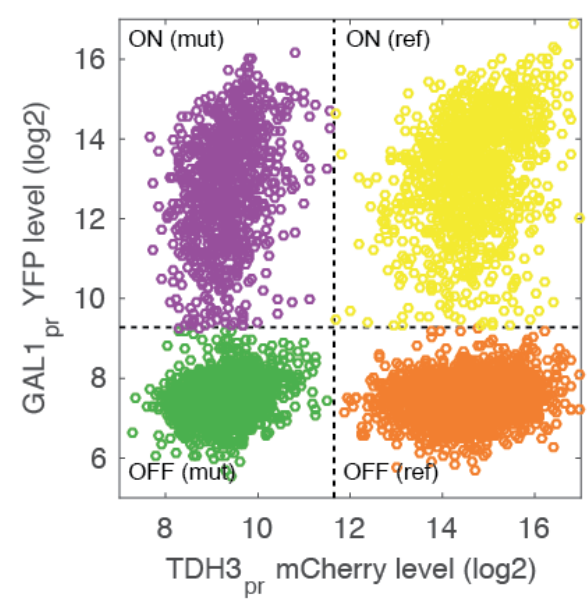

75 Figure S6. Data segmentation example (Figure S6. Related to Figure 2)

76 An example is shown here using data from the first replicate sample for mutant yal068c $\Delta$. Cell

77 debris is filtered from the raw data using a FSC/SSC gate, and the mCherry vs. YFP values of

78 remaining events are plotted. Data is segmented on the mCherry channel to separate reference

79 and mutant strain, and on the YFP channel to separate the induced cells and uninduced cells.

80 The horizontal and vertical dashed lines show the threshold used for segmentation. 


\section{Supplemental tables and legends}

\section{Table S1. Enriched Gene Ontology for genes that significantly affect all four yeast traits (Table}

\section{S1. Relates to Figure 4)}

87 value less than 0.01

\begin{tabular}{|c|c|c|}
\hline GO ID & GO Term & $\begin{array}{c}\text { Corrected P- } \\
\text { Value }\end{array}$ \\
\hline GO:0010467 & gene expression & $9.1 \mathrm{E}-21$ \\
\hline GO:0016070 & RNA metabolic process & $2.1 \mathrm{E}-15$ \\
\hline GO:0034641 & cellular nitrogen compound metabolic process & $2.8 \mathrm{E}-14$ \\
\hline GO:0006807 & nitrogen compound metabolic process & $2.4 \mathrm{E}-13$ \\
\hline GO:0090304 & nucleic acid metabolic process & $5.8 \mathrm{E}-13$ \\
\hline GO:0044260 & cellular macromolecule metabolic process & $1.6 \mathrm{E}-12$ \\
\hline GO:0044271 & cellular nitrogen compound biosynthetic process & $2.2 \mathrm{E}-12$ \\
\hline GO:0043170 & macromolecule metabolic process & $9.1 \mathrm{E}-12$ \\
\hline GO:0034645 & cellular macromolecule biosynthetic process & $1.2 \mathrm{E}-10$ \\
\hline GO:0009059 & macromolecule biosynthetic process & $1.8 \mathrm{E}-10$ \\
\hline GO:0006139 & nucleobase-containing compound metabolic process & $4.2 \mathrm{E}-10$ \\
\hline GO:0043933 & macromolecular complex subunit organization & $2.3 \mathrm{E}-09$ \\
\hline GO:0046483 & heterocycle metabolic process & $3.1 \mathrm{E}-09$ \\
\hline GO:0006725 & cellular aromatic compound metabolic process & $4.2 \mathrm{E}-09$ \\
\hline GO:1901360 & organic cyclic compound metabolic process & $1.4 \mathrm{E}-08$ \\
\hline GO:0044238 & primary metabolic process & 2.7E-08 \\
\hline GO:0006396 & RNA processing & $1.2 \mathrm{E}-07$ \\
\hline GO:0044237 & cellular metabolic process & $1.2 \mathrm{E}-07$ \\
\hline GO:0044249 & cellular biosynthetic process & $3.1 \mathrm{E}-07$ \\
\hline GO:0002181 & cytoplasmic translation & $3.5 \mathrm{E}-07$ \\
\hline GO:0006355 & regulation of transcription, DNA-templated & $3.8 \mathrm{E}-07$ \\
\hline GO:1903506 & regulation of nucleic acid-templated transcription & $3.8 \mathrm{E}-07$ \\
\hline GO:2001141 & regulation of RNA biosynthetic process & $3.8 \mathrm{E}-07$ \\
\hline GO:0071824 & protein-DNA complex subunit organization & 4.1E-07 \\
\hline
\end{tabular}




\begin{tabular}{|c|c|c|}
\hline GO:0010468 & regulation of gene expression & $5.8 \mathrm{E}-07$ \\
\hline GO:0044267 & cellular protein metabolic process & $6.7 \mathrm{E}-07$ \\
\hline GO:0051252 & regulation of RNA metabolic process & $7.2 \mathrm{E}-07$ \\
\hline GO:1901576 & organic substance biosynthetic process & $8.1 \mathrm{E}-07$ \\
\hline GO:0006351 & transcription, DNA-templated & $8.8 \mathrm{E}-07$ \\
\hline GO:0032774 & RNA biosynthetic process & $8.8 \mathrm{E}-07$ \\
\hline GO:0097659 & nucleic acid-templated transcription & $8.8 \mathrm{E}-07$ \\
\hline GO:2000112 & regulation of cellular macromolecule biosynthetic process & $1.2 \mathrm{E}-06$ \\
\hline GO:0071704 & organic substance metabolic process & $1.3 \mathrm{E}-06$ \\
\hline GO:0010556 & regulation of macromolecule biosynthetic process & $1.7 \mathrm{E}-06$ \\
\hline GO:0019219 & regulation of nucleobase-containing compound metabolic process & $2.0 \mathrm{E}-06$ \\
\hline GO:0009058 & biosynthetic process & $2.0 \mathrm{E}-06$ \\
\hline GO:0019538 & protein metabolic process & $2.1 \mathrm{E}-06$ \\
\hline GO:0031326 & regulation of cellular biosynthetic process & 4.3E-06 \\
\hline GO:0009889 & regulation of biosynthetic process & $5.1 \mathrm{E}-06$ \\
\hline GO:0022613 & ribonucleoprotein complex biogenesis & $6.2 \mathrm{E}-06$ \\
\hline GO:0034654 & nucleobase-containing compound biosynthetic process & 7.4E-06 \\
\hline GO:0051171 & regulation of nitrogen compound metabolic process & $8.4 \mathrm{E}-06$ \\
\hline GO:0006325 & chromatin organization & $9.1 \mathrm{E}-06$ \\
\hline GO:0008152 & metabolic process & $1.3 \mathrm{E}-05$ \\
\hline GO:0006412 & translation & $1.3 \mathrm{E}-05$ \\
\hline GO:0060255 & regulation of macromolecule metabolic process & $1.8 \mathrm{E}-05$ \\
\hline GO:0043043 & peptide biosynthetic process & $1.8 \mathrm{E}-05$ \\
\hline GO:0018130 & heterocycle biosynthetic process & $2.8 \mathrm{E}-05$ \\
\hline GO:0034728 & nucleosome organization & $3.3 \mathrm{E}-05$ \\
\hline GO:0043604 & amide biosynthetic process & 3.9E-05 \\
\hline GO:0034660 & ncRNA metabolic process & $3.9 \mathrm{E}-05$ \\
\hline GO:0019438 & aromatic compound biosynthetic process & 4.0E-05 \\
\hline GO:0019222 & regulation of metabolic process & $6.8 \mathrm{E}-05$ \\
\hline GO:0034622 & cellular macromolecular complex assembly & $6.9 \mathrm{E}-05$ \\
\hline GO:0080090 & regulation of primary metabolic process & $8.8 \mathrm{E}-05$ \\
\hline GO:1901362 & organic cyclic compound biosynthetic process & $9.1 \mathrm{E}-05$ \\
\hline GO:0034470 & ncRNA processing & $9.3 \mathrm{E}-05$ \\
\hline GO:0016568 & chromatin modification & $1.0 \mathrm{E}-04$ \\
\hline GO:0042254 & ribosome biogenesis & $1.1 \mathrm{E}-04$ \\
\hline GO:0051276 & chromosome organization & $1.1 \mathrm{E}-04$ \\
\hline GO:0006364 & rRNA processing & $1.2 \mathrm{E}-04$ \\
\hline GO:0031323 & regulation of cellular metabolic process & $1.3 \mathrm{E}-04$ \\
\hline GO:0043486 & histone exchange & $1.3 \mathrm{E}-04$ \\
\hline
\end{tabular}




\begin{tabular}{|c|c|c|}
\hline GO:0006518 & peptide metabolic process & $1.4 \mathrm{E}-04$ \\
\hline GO:0071840 & cellular component organization or biogenesis & $2.4 \mathrm{E}-04$ \\
\hline GO:0030490 & maturation of SSU-rRNA & $3.5 \mathrm{E}-04$ \\
\hline GO:0016072 & rRNA metabolic process & 4.7E-04 \\
\hline GO:0071822 & protein complex subunit organization & $4.8 \mathrm{E}-04$ \\
\hline GO:0043603 & cellular amide metabolic process & 7.3E-04 \\
\hline GO:0065003 & macromolecular complex assembly & $1.1 \mathrm{E}-03$ \\
\hline GO:0044085 & cellular component biogenesis & $1.1 \mathrm{E}-03$ \\
\hline GO:0043044 & ATP-dependent chromatin remodeling & $1.3 \mathrm{E}-03$ \\
\hline GO:0010629 & negative regulation of gene expression & $1.7 \mathrm{E}-03$ \\
\hline GO:0045892 & negative regulation of transcription, DNA-templated & $2.0 \mathrm{E}-03$ \\
\hline GO:0051253 & negative regulation of RNA metabolic process & $2.0 \mathrm{E}-03$ \\
\hline GO:1902679 & negative regulation of RNA biosynthetic process & $2.0 \mathrm{E}-03$ \\
\hline GO:1903507 & negative regulation of nucleic acid-templated transcription & $2.0 \mathrm{E}-03$ \\
\hline GO:0000462 & $\begin{array}{l}\text { maturation of SSU-rRNA from tricistronic rRNA transcript (SSU-rRNA, 5.8S rRNA, } \\
\text { LSU-rRNA) }\end{array}$ & $2.1 \mathrm{E}-03$ \\
\hline GO:0006338 & chromatin remodeling & $3.7 \mathrm{E}-03$ \\
\hline GO:0042274 & ribosomal small subunit biogenesis & $3.8 \mathrm{E}-03$ \\
\hline GO:0010558 & negative regulation of macromolecule biosynthetic process & 4.0E-03 \\
\hline GO:2000113 & negative regulation of cellular macromolecule biosynthetic process & 4.0E-03 \\
\hline GO:0016569 & covalent chromatin modification & $5.0 \mathrm{E}-03$ \\
\hline GO:0016570 & histone modification & $5.0 \mathrm{E}-03$ \\
\hline GO:0006357 & regulation of transcription from RNA polymerase II promoter & $5.7 \mathrm{E}-03$ \\
\hline GO:0051172 & negative regulation of nitrogen compound metabolic process & $8.8 \mathrm{E}-03$ \\
\hline GO:0031327 & negative regulation of cellular biosynthetic process & $9.4 \mathrm{E}-03$ \\
\hline GO:0045934 & negative regulation of nucleobase-containing compound metabolic process & $9.6 \mathrm{E}-03$ \\
\hline
\end{tabular}


Table S2. The number of genes that affect growth rate and each of the three non-growth

91 traits (Table S2. Relates to Figure 4)

92 Genes that significantly affect the unfolded protein response, induced fraction (GAL), and

93 induction level (GAL) were compared to the genes that significantly affect growth rate. The

94 total number of genes that were measured in both growth rate and the other trait is listed. Of

95 this total number, the number that significantly affected growth rate, significantly affected the

96 non-growth rate trait, and significantly affected both traits is listed.

\begin{tabular}{|c|c|c|c|c|}
\hline & $\begin{array}{c}\text { No. genes also } \\
\text { assayed in growth } \\
\text { rate screen }\end{array}$ & $\begin{array}{c}\text { No. genes } \\
\text { significantly affect } \\
\text { growth rates }\end{array}$ & $\begin{array}{c}\text { No. genes } \\
\text { significantly affect } \\
\text { the non-growth rate } \\
\text { trait }\end{array}$ & $\begin{array}{c}\text { No. genes } \\
\text { significantly affect } \\
\text { both }\end{array}$ \\
\hline $\begin{array}{c}\text { Unfolded protein } \\
\text { response }\end{array}$ & 4152 & 779 & 594 & 369 \\
\hline $\begin{array}{c}\text { Induced fraction } \\
\text { (GAL) }\end{array}$ & 3869 & 634 & 595 & 254 \\
\hline Induction level (GAL) & 3869 & 634 & 744 & 316 \\
\hline
\end{tabular}

97 
Table S3. Significantly spatially clustered Gene Ontology (Table S3. Relates to Figure 4)

For each Gene Ontology that is spatially clustered, the direction in the four-trait space is shown,

as well as the $p$-value and false discovery rate (FDR). Significant GOs were defined by FDR $<0.01$.

Table S4. Quantitative screens that are analyzed for gene effect size distribution (Table S3.

Relates to Figure 2)

We manually scanned over 200 published deletion library screens to identify datasets that

could be reanalyzed to potentially determine an effect size distribution. Of these 200 papers,

we found only 6 that contained datasets in a form that was suitable for our reanalysis.

\begin{tabular}{|c|c|c|c|c|}
\hline $\begin{array}{l}\text { First author, } \\
\text { publication } \\
\text { year }\end{array}$ & Trait & $\begin{array}{c}\# \\
\text { Gene } \\
s\end{array}$ & $\begin{array}{c}\text { Source of } \\
\text { published data }\end{array}$ & Reference \\
\hline Breslow, 2008 & $\begin{array}{l}\text { Growth } \\
\text { rate }\end{array}$ & 4204 & $\begin{array}{l}\text { Supplementary } \\
\text { table S5 }\end{array}$ & $\begin{array}{l}\text { Breslow, D. K. et al. A comprehensive strategy } \\
\text { enabling high-resolution functional analysis of the } \\
\text { yeast genome. Nat. Methods 5, 711-718 (2008). }\end{array}$ \\
\hline Schluter, 2008 & $\begin{array}{l}\text { Endosomal } \\
\text { protein } \\
\text { sorting }\end{array}$ & 4814 & $\begin{array}{l}\text { Supplementary } \\
\text { table } 1\end{array}$ & $\begin{array}{c}\text { Schluter, C. et al. Global analysis of yeast endosomal } \\
\text { transport identifies the vps55/68 sorting complex. } \\
\text { Mol. Biol. Cell 19, 1282-1294 (2008). }\end{array}$ \\
\hline $\begin{array}{c}\text { Vizeacoumar, } \\
2010\end{array}$ & $\begin{array}{l}\text { Spindle } \\
\text { morphogen } \\
\text { esis }\end{array}$ & 4286 & $\begin{array}{l}\text { Supplementary } \\
\text { table S6 }\end{array}$ & $\begin{array}{l}\text { Vizeacoumar, F. J. et al. Integrating high-throughput } \\
\text { genetic interaction mapping and high-content } \\
\text { screening to explore yeast spindle morphogenesis. J. } \\
\text { Cell Biol. 188, 69-81 (2010). }\end{array}$ \\
\hline Cooper, 2010 & $\begin{array}{c}\text { Amino acid } \\
\text { level }\end{array}$ & 4382 & $\begin{array}{l}\text { Supplementary } \\
\text { table } 4\end{array}$ & $\begin{array}{l}\text { Cooper, S. J. et al. High-throughput profiling of amino } \\
\text { acids in strains of the Saccharomyces cerevisiae } \\
\text { deletion collection. Genome Res. 20, 1288-1296 } \\
\text { (2010). }\end{array}$ \\
\hline Jonikas, 2009 & $\begin{array}{l}\text { Unfolded } \\
\text { protein } \\
\text { response }\end{array}$ & 4563 & $\begin{array}{l}\text { Supplementary } \\
\text { table } 1\end{array}$ & $\begin{array}{l}\text { Jonikas, M. C. et al. Comprehensive characterization } \\
\text { of genes required for protein folding in the } \\
\text { endoplasmic reticulum. Science 323, 1693-1697 } \\
\text { (2009). }\end{array}$ \\
\hline $\begin{array}{l}\text { Hillenmeyer, } \\
2008\end{array}$ & $\begin{array}{l}\text { Chemical } \\
\text { genomic } \\
\text { profile }\end{array}$ & 5337 & $\begin{array}{l}\text { http://chemoge } \\
\text { nomics.stanfor } \\
\text { d.edu/supplem } \\
\text { ents/global/do } \\
\text { wnload.html }\end{array}$ & $\begin{array}{l}\text { Hillenmeyer, M. E. et al. The chemical genomic } \\
\text { portrait of yeast: uncovering a phenotype for all } \\
\text { genes. Science 320, 362-365 (2008). }\end{array}$ \\
\hline
\end{tabular}




\section{Supplemental Text}

\section{Re-analysis of previous quantitative screening using yeast deletion collections}

111 Since the release of the yeast deletion collection, a large number of studies have been

112 performed (Giaever and Nislow, 2014) potentially providing a rich source to understand the

113 quantitative effects of gene deletions on traits. Unfortunately, the raw data was not published

114 and readily available for all but a small handful of these studies (Table S4).

115 Data from each screen in the Table S4 was analyzed using the following method: 1) download

116 raw data; 2 ) determine the measurement error; 3 ) calculate $p$ value for each gene by

117 comparing effect size measurement to measurement error (two-tailed t-test, assuming

118 measurement error is Gaussian distributed); 4) correct the $p$ values for multiple hypothesis

119 tests by calculating false discovery rate; 5) identify the number of significant genes as ones with

$120 \quad F D R<0.5 \%$.

121 The measurement error for individual assays were determined as below. We assume that the

122 true effects of deleting the $i^{t h}$ gene is $x^{i}$. The two independent measurements, $x^{i, j}=x^{i}+\epsilon^{i, j}$

123 for $j=1,2$, where $\varepsilon$ is the measurement noise term. Assuming that measurement noise follows

124 a Gaussian distribution, i.e. $\epsilon^{i, j} \sim N(0, \sigma)$. The difference of the two measurements on the

125 identical strain will reveal information about the standard deviation of measurement noise.

126 Specifically, since

$$
x^{i, 1}-x^{i, 2} \sim N(0, \sqrt{2} \sigma)
$$


127 we can derive the following estimate of the standard deviation of measurement noise:

$$
\hat{\sigma}=\frac{\sum\left(x^{i, 1}-x^{i, 2}\right)^{2}}{2 *\left(N_{\text {gene }}-1\right)}
$$

128 This method was applied to the raw data from the six assays in Table S4. Breslow et al. had

129 different number of replicates (Breslow et al., 2008), and hence the measurement error for the

130 individual mutants varied depending on the number of replicates. Specifically, among 4204

131 assayed genes, 2809 genes have one measurement, 874 genes have two replicates and 521

132 genes have at least three replicates. To avoid this complication, we only used the data from the

133 first measurements and used the remaining data to estimate the measurement error. We first

134 estimated the measurement error by applying the equation above to the replicate

135 measurements of 874 strains with two measurements and determined measurement error as

136 0.015. Then we calculate the measurement error the 521 strains for which three measurements

137 had been made. This yielded a measurement error of 0.017 . As these two estimations are close,

138 we use the average (0.016) as the measurement error for the assay. We observed that the

139 measurement noise tends to be larger for strains with large effect size, which means that most

140 strains with moderate effect sizes probably have smaller than estimated measurement error.

141 Hence, we do not believe that this method will overestimate the number of genes affecting the

142 growth rate trait.

143 Similarly, mutants in Jonikas et al. had different numbers of replicates (Jonikas et al., 2009).

144 Measurement noise decreased as the number of replicate increased. As a conservative

145 estimate of effect size measurements, we treated all measurements as if they had only two 
146 replicate data. To estimate the measurement error, we used the data from 541 strains with

147 exactly two replicate data. In the original paper, the standard deviation of measurements for

148 each strain was reported. Since there were only two measurements for these strains, the

149 standard deviation equals the half of the difference between two measurements. Assuming

150 that measurement noise of each replicate data followed $N(0, \sigma)$, the expectation of the half of

151 the difference of two independent measurements is $\sigma / \sqrt{\pi}$. When plotting the histogram of this

152 data, we found that a number of measurement have exceptionally large measurement error,

153 which artificially increased our estimation. After removing strains with measurement error

154 larger than 0.5, the resulting measurement standard deviation has an average as 0.0678. Hence,

155 we estimated the measurement noise as $\frac{\sigma}{\sqrt{2}}=0.0678 * \sqrt{\frac{\pi}{2}}=0.085$.

156 Mutants in Schluter et al. were assayed in replicates for both haploid and diploid

157 strains(Schluter et al., 2008). We applied the equation above to this data and determined that

158 the measurement error was 0.027 for the MATa, haploids, 0.021 for the MATalpha haploids,

159 and 0.042 for diploids. We used the average of these three to estimate measurement error

160 (0.030). Vizeacoumar et al. provided p values for each mutants in the assay (Vizeacoumar et al.,

161 2010). We convert the $p$ value back to a $z$-score using Matlab function norminv(). While Copper

162 et al. published raw data, they did so for only one replicate and hence we did not proceed with

163 further analysis on this data set (Cooper et al., 2010).

164 Furthermore, we analyzed the raw data from Hillenmeyer by comparing the measured effect

165 sizes in independent experiments using the same condition (drug name, dosage and the

166 duration to apply the drug) in separate batches (Hillenmeyer et al., 2008). We found a large 
167 variation of the reproducibility between these replicates, determined as the pair-wise Pearson

168 correlation coefficient (ranging from -0.2 to 0.99 with a median of 0.36 depending on the

169 condition used). Hence we did not analyze the data further more.

170 To evaluate the number of gene deletions that significantly affected each of the quantitative

171 trait, we first considered a null model where all gene deletions had no effects on the assayed

172 traits. We expected the measured effect sizes to follow a normal distribution determined by

173 measurement noise, i.e. $\sim N(0$, measurement noise). However, we found this was not the case

174 for all the traits that we analyzed. To better illustrate this, we re-scaled the effect sizes by

175 measurement error for each trait, and plotted the histograms of the re-scaled effect sizes for

176 the gene deletions that have effect sizes at least 3-fold of the estimated measurement noise in

177 Figure S2. We found the distributions were continuous. Note that only about (1-

$17899.7 \%) * 5000=15$ genes were expected from the noise distribution. This suggests that the

179 measured effects of most of the plotted genes were not from the measurement noise. Note

180 that the data from Vizeacoumar was not shown here as the majority of genes have effects that

181 are within three-fold of measurement noise.

182 To identify assays that are sensitive enough the measure the effect sizes of as many genes as

183 possible. We estimated the number of genes that significantly affect each of the analyzed traits

184 by comparing the measured effect sizes to measurement noise. Using a cutoff of FDR $<0.5 \%$,

185 we determined that two screens by Jonikas et al. and Breslow et al. are suitable for effect size

186 distribution analysis as they have smallest measurement errors.

187 Flow cytometry data processing 
188 Raw data was exported from an LSRII or Stratedigm in fcs3.0 file format. All data was loaded

189 using customized MATLAB code. In briefly, data from each sample was first filtered on FSC/SSC

190 channel to remove cell debris, and on SSC channel to normalize for cell size. The FSC/SSC gates

191 were drawn manually on pooled samples. The SSC gate was determined to include events

192 between the $25^{\text {th }}$ to $75^{\text {th }}$ percentiles of the pooled sample. Pooled samples were also used to

193 find thresholds on YFP and mCherry channels to segment induced vs. uninduced cells, and

194 reference vs. mutant cells (Figure S6 as an example). Mutants were filtered to ensure that there

195 are at least 700 events for both reference and mutant cells in at least one biological replicates.

196 Mutants in twelve plates in replicate one of the GAL screen have higher induced fraction than

197 the reference strain in the same sample. Data from the second replicate were used for these

198 mutants in the future analysis. For the PHO screen, we calculated the standard deviation of the

199 effect size differences between two replicates for each of the three traits. The effect size

200 measurements for fourteen mutants are greater than five-fold of these standard deviations.

201 These strains were filtered from future analysis.

202 Principal component analysis on reporter expression distribution of the entire deletion

203 collection

204 Yeast responds to a mixture of glucose and galactose in a bimodal way. We measured

205 expression level of GAL1pr-YFP in single cells for each of the mutant strain in the deletion

206 collection. We generally observed that the reproducibility was higher when normalizing the

207 distribution by comparing the mutant distribution to the reference distribution in the same well 
208 (see the section Data Normalization for details); as opposed to analyzing the mutant data

209 directly. This is presumably due to slight variation between wells, plates, and days.

210 To find appropriate metric by which to analyze the mutant strains, we performed PCA analysis.

211 We did this by pooling reference and mutant YFP distribution from two replicates. After data

212 segmentation, the GAL1pr-YFP distributions of both reference strain and mutant strain were

213 binned into 92 equally size log2 bins ranging from the maximum to minimum value. Data was

214 normalized to probability distribution, separately for reference strain and mutant strain in each

215 sample. PCA results were shown in Figure S1. The first three principle components explain 60\%

216 variation. By manually examining the shape of each principle component, we could provide a

217 plausible biological explanation for the major components. The first vector affects the induced

218 fraction without affecting the expression level. The second vector has two effects, shifting the

219 expression level of induced cells as well as changing the fraction of induced cells. The third

220 vector change the expression level of both uninduced cells (basal level) and induced cells. In

221 further analysis, we found that the expression level of uninduced cells could not be accurately

222 determined for the majority of strains in our assay for GAL1pr-YFP reporter, and hence only the

223 induced fraction and the induction level are used in the main text. This third metric was used

224 for analysis of the PHO response.

\section{Data normalization}

226 The induced fraction and induction level traits were calculated for each mutant strain using the

227 following method. First, the induced fraction and induction level were calculated for reference

228 strains and query strain in each sample. The induced fraction was calculated as the ratio of the 
229 number of induced events over the number of all events. The induction level was calculated as

230 the average level of YFP of the induced cells. For both traits, the mutant value was regressed

231 against the reference value using the Matlab function robustfit(). The residual of each

232 measurement from the fit was averaged between two replicates to determine the final values

233 of the induced fraction and the induction level.

234 Estimate the number of genes that affect yeast quantitative traits

235 The noise distribution determined from measurement noise estimation was overlaid with the

236 actual effect size measurements. Both curves were normalized to the total number of genes.

237 The area of the region where the actual effect size distribution was outside the measurement

238 noise distribution was determined for estimating the number of genes that affected each of the

239 four yeast traits (Figure S2).

240 Compare the number of detected mutants by using induced fraction and induction level vs.

241 average expression level

242 Our screening data on the yeast galactose response provided a test for estimating the total

243 number of significant mutants using different metrics. This is interesting as many biological

244 traits could usually be defined in different ways, yet it was unclear to our knowledge how much

245 potentially subtle differences in metric could influence genes identified. Here when we are

246 referring to different metrics it is probably easiest to think of them as different sub

247 measurements. For example, if one measured standing height as opposed to sitting height,

248 would one uncover different sets of genes. In our case, the effect of gene deletion on galactose 
249 response can be represented as the two GAL traits as used in the main text, or alternatively we

250 could simply use the average YFP level as used in Jonikas et al (Jonikas et al., 2009). To estimate

251 such effects, we re-analyzed our data by quantifying not just the two GAL traits, but also the

252 average YFP level. After applying the same method to detect mutants that significantly affect

253 yeast GAL response, we found that the two-traits method detected more mutants (1104) than

254 the average YFP method (593). In addition, the one-trait method could not reveal the distinct

255 modes by which different mutants worked; i.e. 50\% reduction in average can come because $50 \%$

256 of cells don't induce or $100 \%$ of cells are $50 \%$ less induced. Hence our data suggested that,

257 biological meaningful decomposition of a complex trait will increase detection sensitivity, and

258 provides new biology insights to understand traits.

\section{Genes that saturated our assay}

260 Our GAL assay was designed to detect genes of small effect size, and as a result, ten genes of

261 larger effect size saturated our assay. These genes were manually verified by inspecting the YFP

262 distribution of the raw data. These genes are: GAL4 (YPL248C), GCN4 (YELO09C), GAL80

263 (YMLO51W), GAL1 (YBR020W), SNF3 (YDL194W), STI1 (YOR027W), REG1 (YDR028C), GAL3

264 (YDR009W), SNF2 (YOR290C), HSC82 (YMR186W). This is important when calculating the

265 explained heritability for top $\mathrm{N}$ genes (see main text). One of our main arguments is that the

266 number of genes that affect a quantitative trait is around $8 \%$ of the genome. If the true effects

267 of these ten genes is much larger than what we estimated, the number of genes that affect a

268 quantitative trait could be smaller. 
269 When using the nominal values of the measurements as effect sizes of these genes, we

270 determined that the total contribution of these genes are $25.2 \%$ and $7.5 \%$ for induction level

271 and induced fraction respectively. As another way to estimate the effect sizes of these genes,

272 we randomly sampled the effect size distribution. The average contribution of these genes is

$27327.8 \%$ and $10.5 \%$ respectively, suggesting that this alternate method does not strongly affect

274 conclusion.

275 Overlapping among genes that are significant for each of the four studied traits

276 We examined the overlap between significant genes that affect growth rate and ones that

277 affect each of the three other non-growth traits. To do so, genes with missing data in one of the

278 data sets were removed. The result is in Table S2. The p-value was calculated between each

279 pair of growth rate and non-growth rate trait, using a hypergeometric test (one-tailed).

280 Compare the effects on GAL and PHO response by deleting genes involved in protein

281 synthesis

282 For 95 genes involved in protein synthesis, we compared their effects on GAL and PHO traits in

283 the main text and Figure S5 using t-test (two-tailed). The average difference between the

284 effects on GAL and PHO is 0.15 . The standard deviations of effects on GAL and PHO are 0.21

285 and 0.10. As an alternative method to test for significance, we pooled the measured effects on

286 GAL and PHO response and randomly split the pooled data into two groups for 1,000,000 times

287 and calculated the difference between two groups. The observed difference (0.15) is not

288 observed in the randomized sample. Hence we determined that $p<10^{-6}$ using this method. 
289 Canonical genes involved in galactose signaling and unfolded protein response

290 Glu/Gal gene list: GPB2, IRA1, TOS1, GLK1, GPA2, GAL83, SAK1, GLC7, YCK1, BCY1, RGT1, ELM1, 291 TPK3, HXK1, GPR1, RGT2, SNF3, REG1, MTH1, MSN5, SIP1, SNF1, MIG1, SNF4, SIP2, PDE1, HXK2,

292 CYR1, TPK1, GRR1, SDC25, CDC25, SIP5, RAS2, YCK2, IRA2, STD1, RAS1, RGS2, PDE2, GPB1, TPK2, 293 GAL1, GAL3, GAL80, GAL4, SNF2, GCN4, HSC82, STI1

294 Gene localized in ER, Golgi, and early Golgi are (298 genes): YELO31W, YJR117W, YFLO25C,

295 YJL062W, YML012W, YAL023C, YJR118C, YML055W, YML013W, YOR002W, YGL084C, YCR044C,

296 YER122C, YNL219C, YNR030W, YDL095W, YML115C, YGLO20C, YGLO54C, YILO39W, YELO36C,

297 YPL227C, YOL013C, YMR022W, YMR161W, YKL212W, YDL192W, YLR110C, YGL167C, YMR264W,

298 YALO58W, YER083C, YDR027C, YLR372W, YCR094W, YLR268W, YNL238W, YMR307W, YJLO29C,

299 YBR171W, YDL100C, YGL226C-A, YBR106W, YJR073C, YNL322C, YGR229C, YGR284C, YJR010C-A,

300 YML128C, YFR041C, YNL323W, YEL042W, YMR123W, YBR015C, YJR075W, YBR162W-A,

301 YCR067C, YJL004C, YCR017C, YAL026C, YOR216C, YIL090W, YAL007C, YNL041C, YJL123C,

302 YILO4OW, YBR164C, YCL045C, YNL051W, YIR004W, YPLO50C, YPL051W, YGL126W, YCR034W,

303 YMR292W, YDR233C, YNL297C, YGL005C, YDR245W, YBR036C, YDR221W, YPL192C, YLL014W,

304 YDR508C, YEL001C, YER005W, YDR137W, YDL099W, YGL231C, YHR108W, YMR238W, YALO53W,

305 YILO27C, YER072W, YML038C, YER120W, YELO27W, YILO30C, YDR492W, YJR131W, YMR010W,

306 YHR181W, YPR063C, YIL124W, YLR350W, YJR088C, YBL011W, YMLO48W, YNLO44W, YDR358W,

307 YOR311C, YDR411C, YMR272C, YNL049C, YMR015C, YDL052C, YJR134C, YKLO96W, YNL280C,

308 YLR194C, YER113C, YDR077W, YDR055W, YNR021W, YNL327W, YLR130C, YNR039C, YJL099W,

309 YKL146W, YPRO03C, YHLO17W, YOR245C, YER166W, YBR132C, YOR016C, YPR090W, YNL300W, 
310 YLR250W, YGR038W, YPL259C, YPR071W, YKLO65C, YKLO46C, YPL274W, YELO48C, YOR317W,

311 YDR100W, YNL146W, YMR253C, YJR031C, YER011W, YJL078C, YILO16W, YML037C, YGR247W,

312 YFLO04W, YBR023C, YILO44C, YMR052W, YDL204W, YBR067C, YDR153C, YIL043C, YNL095C,

313 YDR476C, YOR307C, YOR321W, YCR011C, YMR237W, YMR071C, YER004W, YPR028W, YGL255W,

314 YPL170W, YKL063C, YJL044C, YLR023C, YMR215W, YMR251W-A, YGR261C, YPR091C, YDR056C,

315 YLLO28W, YLR330W, YBLO10C, YNR019W, YGL124C, YDR294C, YNLO46W, YDR519W, YKR088C,

316 YLR042C, YKL094W, YCR048W, YCR043C, YDR084C, YKR067W, YJL196C, YLLO61W, YML101C,

317 YDL232W, YOLO30W, YMR054W, YDR410C, YBR273C, YLR120C, YHR110W, YORO44W, YDL137W,

318 YJL171C, YOR285W, YMR029C, YLR064W, YPL137C, YOR092W, YBR159W, YGLO83W, YNL156C,

319 YDL128W, YBR296C, YOR175C, YJL198W, YOL101C, YHL019C, YJL117W, YGR263C, YML059C,

320 YOR214C, YNR013C, YOR087W, YJL192C, YGR177C, YBL102W, YPL195W, YLL052C, YLR390W-A,

321 YDR264C, YOR299W, YMR152W, YLL055W, YDR424C, YBR287W, YELO4OW, YNL125C, YHLO03C,

322 YBR283C, YDL121C, YHR045W, YNR075W, YOR377W, YHR039C, YGLO1OW, YCLO25C, YNR044W,

323 YLR050C, YOL137W, YOL107W, YDL018C, YDR307W, YDR297W, YNL190W, YDR503C, YBR177C,

324 YGR266W, YER019C-A, YLR034C, YOR322C, YGR260W, YDR349C, YJR015W, YPL246C, YMR058W,

325 YBR290W, YLL023C, YDR205W, YHR123W, YJLO24C, YJL212C, YLR292C, YPL207W, YKR027W,

326 YILO76W, YBR288C, YJL183W, YKL008C, YJL207C, YML067C, YGR089W, YOR291W, YNL111C,

327 YELO43W, YPL234C, YLR056W, YKL096W-A, YGR157W, YHRO60W, YLR039C, YHR079C

\section{Reference:}

329 Boyle, E.I., Weng, S., Gollub, J., Jin, H., Botstein, D., Cherry, J.M., Sherlock, G., 2004. 
Breslow, D.K., Cameron, D.M., Collins, S.R., Schuldiner, M., Stewart-Ornstein, J., Newman, H.W., Braun, S., Madhani, H.D., Krogan, N.J., Weissman, J.S., 2008. A comprehensive strategy enabling high-resolution functional analysis of the yeast genome. Nature Methods 5, 711718. doi:10.1038/nmeth.1234

Cooper, S.J., Finney, G.L., Brown, S.L., Nelson, S.K., Hesselberth, J., MacCoss, M.J., Fields, S., 2010. High-throughput profiling of amino acids in strains of the Saccharomyces cerevisiae deletion collection. Genome Research 20, 1288-1296. doi:10.1101/gr.105825.110

Giaever, G., Nislow, C., 2014. The yeast deletion collection: a decade of functional genomics. Genetics 197, 451-465.

Hillenmeyer, M.E., Fung, E., Wildenhain, J., Pierce, S.E., Hoon, S., Lee, W., Proctor, M., St Onge, R.P., Tyers, M., Koller, D., Altman, R.B., Davis, R.W., Nislow, C., Giaever, G., 2008. The Chemical Genomic Portrait of Yeast: Uncovering a Phenotype for All Genes. Science 320, 362-365. doi:10.1126/science.1150021

Jonikas, M.C., Collins, S.R., Denic, V., Oh, E., Quan, E.M., Schmid, V., Weibezahn, J., Schwappach, B., Walter, P., Weissman, J.S., Schuldiner, M., 2009. Comprehensive characterization of genes required for protein folding in the endoplasmic reticulum. Science 323, 1693-1697. doi:10.1126/science.1167983

Schluter, C., Lam, K.K.Y., Brumm, J., Wu, B.W., Saunders, M., Stevens, T.H., Bryan, J., Conibear, E., 2008. Global analysis of yeast endosomal transport identifies the vps55/68 sorting complex. Mol. Biol. Cell 19, 1282-1294.

Vizeacoumar, F.J., van Dyk, N., Vizeacoumar, F.S., Cheung, V., Li, J., Sydorskyy, Y., Case, N., Li, Z., Datti, A., Nislow, C., Raught, B., Zhang, Z., Frey, B., Bloom, K., Boone, C., Andrews, B.J., 2010. Integrating high-throughput genetic interaction mapping and high-content screening to explore yeast spindle morphogenesis. The Journal of Cell Biology 188, 69-81.

doi:10.1083/jcb.200909013 